\title{
Los conciertos en Barcelona (1760-1808): el doble estreno de La Creación de Haydn en contexto
}

\section{Concerts in Barcelona (1760-1808): the Double Premiere of Haydn's Creation in Context}

Barcelona carecía de un estudio sistemático de las primeras etapas de su vida concertística. A partir de los datos y la óptica del dietario del barón de Maldà y del Diario de Barcelona, este artículo estudia la organización y la evolución de los distintos formatos de conciertos en la ciudad entre 1760 y 1808 . La vitalidad de las siestas musicales se considera desde su dimensión estética y social y desde su identidad compartida con los conciertos espirituales domésticos. Las academias domésticas por suscripción, en el punto de encuentro entre estos últimos y el naciente concierto público, se presentan como un espacio de negociación cultural clave para la evolución de las prácticas musicales urbanas. Por fin, a partir de este marco y con datos inéditos, se analiza la exitosa pero compleja recepción en Barcelona del oratorio La Creación de Joseph Haydn a través de la sucesión de conciertos públicos de 1804 y 1805.

Palabras clave: siesta musical, oratorio, academia (concierto), concierto doméstico, concierto público, recepción, Joseph Haydn, Die Schöpfung (oratorio), Barcelona, barón de Maldà, historia musical urbana.

To date there has been no systematic study of early concert life in Barcelona. Based on the information and perspective of the diary of the Baron of Malda and the Diario de Barcelona, this article examines the organisation and evolution of the different concert formats in the city between 1760 and 1808. The vitality of musical siestas is considered from their aesthetic and social dimension, and from their shared identity with domestic spiritual concerts. Domestic academies by subscription, the point of contact between the latter and the nascent public concert, are presented as an area of cultural negotiation, key to the evolution of urban musical practices. Finally, this framework and unpublished data is used to analyse the successful but complex reception of Joseph Haydn's oratorio The Creation in Barcelona through a series of public concerts in 1804 and 1805.

Keywords: musical siesta, oratorio, academy (concert), domestic concert, public concert, reception, Joseph Haydn, Die Schöpfung (oratorio), Barcelona, Baron of Maldà, urban music history.

\footnotetext{
${ }^{1}$ Este artículo se enmarca en los trabajos del proyecto de investigación HAR2014-53143-P (20152018) del Ministerio de Economía y Competitividad desarrollado por el Grupo de Investigación "Música en España en la Edad Moderna: composición, recepción e interpretación" (www.unirioja.es/mecri). Es una versión revisada de la ponencia presentada en el congreso internacional "El concierto en España (ss. XVIII-XXI): aspectos históricos, productivos, interpretativos e ideológicos" (Madrid, Universidad Complutense, 23-24 de noviembre de 2017). Merecen un agradecimiento especial, por las sugerencias que han aportado y los datos que me han facilitado, Oriol Brugarolas, Miguel Ángel Marín, Josep Martínez y Elena Pons.
} 
El 5 de marzo de 1801, en su dietario, Rafael d'Amat i de Cortada (17461819), barón de Maldà, trazaba un panorama del estado de la música en Barcelona $^{2}$. Lo dividía en tres ámbitos espaciales y los organizaba jerárquicamente. Presentaba, en primer lugar, los oratorios en las iglesias, es decir, las siestas musicales en su máxima expresión. Seguían las academias caseras por suscripción, entre las que Maldà destacaba, por su calidad, las del padre Josep Prats, primer violín de la capilla de música de la catedral.Y, por último, Maldà trataba de las óperas italianas en el teatro, aunque admitía que eran estas las que habían "influido en el gusto que reina hoy en día en obras de música"’. Significativamente, el concierto público no tenía todavía entidad suficiente para figurar en esta categorización de la vida musical urbana.

Maldà, gran melómano y músico aficionado, pero indiferente, cuando no hostil, al mundo teatral, manifiesta unas prioridades opuestas a las del discurso publicado dominante en su época, que tendía a considerar el teatro, "rendez vous de todos los hombres de buen gusto, y primer paradero de los que de una en otra posta andan corriendo el mundo", como la principal vitrina de la cultura musical urbana. Desde su particular subjetividad, el testimonio de Maldà tiene la innegable ventaja de decirnos algo sobre una experiencia sensible y social de la música profundamente arraigada en un lugar y en una comunidad concretas, la Barcelona acomodada y devota de la segunda mitad del siglo XVIII ${ }^{5}$.

Miguel Ángel Marín, en su sugerente síntesis sobre el concierto en la España del siglo XVIII, señala acertadamente que los límites entre los distintos formatos de conciertos "aparecen con frecuencia difuminados", especialmente en las fronteras de lo público y lo privado y de lo sacro y lo profano $^{6}$. Sin renunciar a la indiscutible operatividad de una clasificación retrospectiva de este tipo, las jerarquías y los usos terminológicos de Maldà,

\footnotetext{
2 Arxiu Històric de la Ciutat de Barcelona (AHCB), Ms. A 222, Calaix de sastre (CdS) XXII, pp. 206210 (5-3-1801). Este texto fue transcrito por Roger Alier: Lòopera a Barcelona. Orígens, desenvolupament i consolidació de l'òpera com a espectacle teatral a la Barcelona del segle XVIII, Barcelona, Institut d'Estudis Catalans-Societat Catalana de Musicologia, 1990, pp. 471-472.

3 "Són, pues, las òperas las que han influhít lo gust que reyna en el dia en obras de música [...]". AHCB, Ms. A 222, CdS XXII, pp. 206-210 (5-3-1801)

${ }^{4}$ El Caxon de sastre cathalan, Barcelona, en la Imprenta de la Gaceta y en la Libreria de Carlos Gibért, calle del Call, [1761], n. ${ }^{\circ} 3$, p. [30] (http://mdc2.cbuc.cat/cdm/ref/collection/caxon1761/id/26, consulta 24-9-2018).

${ }^{5}$ Para el estudio de un caso análogo, el del diario del abogado de Burdeos Pierre Bernadeau, véase Natalie Morel-Borotra: "Pierre Bernadau antidilettante: un avocat aux concerts du Musée de Bordeaux (1787-1792)", Le Musée de Bordeaux et la musique, 1783-1793, Patrick Taïeb, Natalie Morel-Borotra, Jean Gribenski (dirs.), Mont-Saint-Aignan, Publications des Universités de Rouen et du Havre, 2005, pp. 99-122.

${ }^{6}$ Miguel Ángel Marín: "Escuchar la música: la academia, el concierto y sus públicos", Historia de la música en España e Hispanoamérica. 4. La música en el siglo XVIII, José Máximo Leza (ed.), Madrid, Fondo de Cultura Económica, 2014, pp. 461-462.
} 
al situar las divisiones semánticas allí donde no las esperamos, resultan útiles para repensar algunas de estas categorías. Gracias a Maldà, podemos acercarnos a algunos usos locales y particulares de los principales términos utilizados en la época para referirse a manifestaciones musicales que hoy asociaríamos con situaciones de concierto: concierto [concert], academia, serenata, diversión [diversió o divertiment] de música, función [funció] y siesta. Así, el texto que sigue, además de presentar sucintamente los resultados reunidos y sistematizados en el Apéndice 1, es también un ensayo de lectura de la vida concertística barcelonesa de la segunda mitad del siglo XVIII desde la óptica del barón de Maldà. La parte final muestra, a partir del ejemplo del doble estreno barcelonés del oratorio La Creación [Die Schöpfung] (Hob. XXI:2) de Joseph Haydn y de las dificultades que supuso para el medio musical de la época, cómo las transformaciones en la vida musical del doble cambio de siglo, con el surgimiento del concierto público y la crisis del modelo de las academias por suscripción, alteraron el marco de comprensión planteado por Maldà.

Este trabajo se basa principalmente en dos fuentes: por un lado, el $\mathrm{Ca}$ laix de sastre (CdS), el riquísimo conjunto de dietario y textos misceláneos escritos principalmente en catalán entre 1769 y 1819 por el barón de Maldà7; por otro, el Diario de Barcelona $(D d B)$, que no empezó a publicarse hasta el 1 de octubre de $1792^{\circ}$. Respecto al Calaix de sastre, debemos señalar que los datos presentados aquí son el resultado de una lectura exhaustiva del dietario original entre los años 1769 a 1790 inclusive y de una lectura selectiva de los años posteriores hasta 1816, basada en los índices manuscritos del Arxiu Històric de la Ciutat de Barcelona ${ }^{9}$, la antología en 11 volúmenes publicada por Ramon Boixareu ${ }^{10}$ y el trabajo monográfico de José Reche Antón y Oriol García Molsosa sobre la década de $1790^{11}$.

${ }^{7}$ Para una introducción al corpus textual del barón de Maldà, Margarida Aritzeta: "Introducció general", Rafael d'Amat i de Cortada, Baró de Maldà. Viles i ciutats de Catalunya, Barcelona, Barcino, 1994, pp. 11-70.

${ }^{8}$ Agradezco de forma muy especial a Oriol Brugarolas que me haya permitido contrastar mis notas con la valiosísima colección de noticias musicales del Diario de Barcelona que ha reunido en Oriol Brugarolas (ed.): La música en el Diario de Barcelona, 1792-1850. Prensa, sociedad y cultura cotidiana a principios de la Edad Contemporánea, Barcelona, Calambur, 2018. La totalidad del Diario de Barcelona entre los años 1792 y 1862 puede consultarse en el Arxiu de Revistes Catalanes Antigues (ARCA): http://www.bnc.cat/digital/arca/index.php (consulta 24-9-2018).

${ }^{9}$ En AHCB, existen índices manuscritos de nombres, lugares y materias para los volúmenes Ms. A 204 (año 1789) y Ms. A 207 a 228 (1792-1804), exceptuando el Ms. A 222 (primera parte de 1801), no siempre exhaustivos, pero de gran utilidad para el investigador.

${ }^{10}$ Rafel d'Amat i de Cortada, Baró de Maldà: Calaix de sastre, I: 1769-1791, selecció i edició de Ramon Boixareu, Barcelona, Curial, 1987. Siguieron, hasta 2003, en la misma editorial, diez volúmenes más que cubren hasta el año 1816 inclusive del dietario.

${ }^{11}$ José Reche Antón, Oriol García Molsosa: "Las lluhidas academias de musica". Una aproximació a la professió de músic a la Barcelona de finals del segle XVIII a través de les acadèmies comentades pel Baró de Maldà i l'estudi del clarinet Xuriach MDMB1568, tesina de máster inédita, Escola Superior de Música de Catalunya-Universitat Autònoma de Barcelona, 2012. 
El cuadro del Apéndice 1 presenta la lista más sistemática y completa publicada hasta la fecha sobre la oferta concertística en Barcelona entre 1760 y 1808, junto con el detalle de las fuentes de cada acontecimiento musical citado.

A finales de la década de 1970, basándose ya en estas dos fuentes, Roger Alier dio a conocer una serie de trabajos que modificaron de forma determinante el conocimiento de la vida musical barcelonesa en el tránsito del siglo XVIII al XIX ${ }^{12}$. En el artículo que consagró a los primeros conciertos públicos en Barcelona, Alier presentaba la "escasísima bibliografia" previa sobre el tema ${ }^{13}$. Solo el estudio clásico de Francisco Virella i Cassañes sobre la ópera en Barcelona (1888) y los libros de historia urbana de Jaume Carrera i Pujal y Rafael Tasis ofrecían datos útiles sobre la cuestión ${ }^{14}$. Entre las pocas publicaciones que han enriquecido posteriormente el panorama dibujado por Alier, cabe citar el trabajo de Reche Antón y García Molsosa, así como la integración del caso barcelonés en una historia de la música de ámbito estatal llevada a cabo por Miguel Ángel Marín para el siglo XVIII y por Juan José Carreras para el XIX ${ }^{15}$.

En su estado de la cuestión, sin embargo, Alier no mencionaba otros textos del propio Virella que ahondaban en la historia de los conciertos en la ciudad. En el espíritu polémico de sus artículos de crítica,Virella consideraba la interpretación del oratorio La Creación de Joseph Haydn en la sala de los veleros y en el gran salón del Palau en 1804 como la manifestación de un primer y esperanzador impulso filarmónico frustrado más tarde por el inmoderado italianismo del público barcelonés, causa principal del "retraso" musical de la ciudad ${ }^{16}$. El prestigio durable de la obra de Haydn

12 Roger Alier: "Los primeros conciertos públicos en Barcelona", Estudios Pro Arte, 6, abril-junio 1976, pp. 47-55; id.: "Els primers concerts públics a Barcelona", Serra d’Or, 15-5-1977, pp. 47-49 (versión catalana un poco distinta del artículo anterior); id.: "La vida musical de Barcelona vista a través del 'Calaix de sastre' del baró de Maldà”, Serra d’Or, 221, 15-2-1978, pp. 51-55. Cabe añadir su tesis defendida en 1979, aunque no publicada hasta 1990: Lòpera a Barcelona orígens, desenvolupament i consolidació de l'òpera com a espectacle teatral a la Barcelona del segle XVIII, Barcelona, Institut d'Estudis Catalans-Societat Catalana de Musicología, 1990.

${ }^{13}$ R. Alier: "Els primers concerts públics...", p. 47.

${ }^{14}$ Francisco Virella Cassañes: La ópera en Barcelona. Estudio histórico-crítico, Barcelona, Establecimiento Tipográfico de Redondo y Xumetra, 1888; Jaume Carrera i Pujal: La Barcelona del segle XVIII, Barcelona, Bosch, 1951; Rafael Tasis: Barcelona. Imatge i Història d'una ciutat, Barcelona, Rafael Dalmau, 1961. Carrera i Pujal fue el primero en ofrecer una descripción de la vida concertística de Barcelona a partir de una cuidadosa lectura de Maldà.

15 J. Reche Antón, O. García Molsosa: "Las lluhidas academias de música”...; M. Á. Marín: "Escuchar la música...", pp. 461-484; Juan José Carreras: "El legado ilustrado del concierto", Historia de la música en España e Hispanoamérica. 5. La música en España en el siglo XIX, Juan José Carreras (ed.), Madrid, Fondo de Cultura Económica, 2018, pp. 308-327.

${ }^{16}$ La primera mención al estreno de La Creación en 1804, en F. Virella Cassañes: La ópera..., p. 240. Véanse, sobre todo, los artículos reunidos en F. Virella Casañes: Estudios de crítica musical. Colección de artículos escogidos, Barcelona, Tip. "La Publicidad" de Ronsart y C. a , 1893, pp. 170-171, 307-308, 331 y 411. 
servía implícitamente a Virella como punto de referencia a partir del cual juzgaba como decadentes todas las iniciativas concertísticas ulteriores. Solo el punto de inflexión de las décadas de 1860 y 1870, cuando el gusto de una parte creciente de los músicos y del público viró hacia el canon musical germánico, señalaba, para él, la reconexión con aquel primer y efímero arranque filarmónico ${ }^{17}$. En tiempos mucho más recientes, Marín y Carreras, si bien no han negado la dimensión excepcional de este acontecimiento, lo han encuadrado en el marco de la amplia e intensa recepción española de la música de Haydn a partir de la década $1770^{18}$. Aportamos aquí, junto con algunos datos inéditos, un trabajo más contextualizado que permite matizar estos resultados previos al ubicar el estreno de La Creación de Haydn en un contexto local en plena mutación, como fruto de un efecto de moda, la que generó la fama internacional de Haydn, de la decidida iniciativa de unos pocos agentes y, al mismo tiempo, de los juegos de rivalidades que atravesaban la sociedad urbana acomodada.

\section{Las siestas y las funciones domésticas}

Otros autores ya han señalado la abundancia de música en los templos y la dimensión de recreo y solaz de los numerosos oratorios de corte italianizante que se interpretaban en ellos antes incluso del establecimiento de las temporadas regulares de ópera en $1750^{19}$. El oratorio -como el Stabat Mater o el Miserere que solía sustituirlo durante la Cuaresma- resultaba ser solo la modalidad más brillante de un abanico bien graduado y tarifado de opciones que incluía también la modesta siesta a cuatro, la siesta grande (siesta grossa), con violines o con violines y vientos, y el rosario cantado con distintas plantillas ${ }^{20}$. La importancia del fenómeno en Barcelona puede medirse en cifras. Si nos atenemos solo a los oratorios, he podido contar,

\footnotetext{
${ }^{17}$ Para un excelente análisis de este cambio en el gusto en Madrid, que Virella presentaba como un modelo para la capital catalana, véase Judith Etzion: "Música Sabia': The Reception of Classical Music in Madrid (1830s-1860s)", International Journal of Musicology, 7, 1998, pp. 185-232; y F. Virella Casañes: Estudios de crítica musical..., pp. 307, passim.

${ }^{18}$ M. Á. Marín: "Joseph Haydn y el Clasicismo vienés en España", Historia de la música en España e Hispanoamérica. 4. La música en el siglo XVIII..., pp. 484-500; J. J. Carreras: "La recepción de la música alemana", Historia de la música en España e Hispanoamérica. 5. La música en España en el siglo XIX..., pp. 327-347.

${ }_{19}^{19}$ R. Alier: "La vida musical a Barcelona...", p. 52; Francesc Bonastre: "La música a Catalunya al segle XVIII", Història de la cultura catalana. III. El Setcents, Barcelona, Edicions 62, 1996, pp. 264-265.

${ }^{20}$ Lluís Bertran: Musique en lieu: une topographie de l'expérience musicale à Barcelone et sur son territoire (1760-1808), tesis doctoral inédita, Université de Poitiers y Universidad de La Rioja, 2017, pp. 184-187. Para algunas categorizaciones de las siestas hechas en la época, Francesc Bonastre: "La capella musical de la Seu de Tarragona a mitjan segle XVIII", Boletín Arqueológico. Órgano de la Real Sociedad Arqueológica Tarraconense, Época IV, Fascs. 133-140, 1976-1977, pp. 259-270; Josep Pavia i Simó: "Documents per a la història de les capelles de música de Barcelona aa. 1763-1820", Anuario Musical, 37, 1982, pp. 99-128.
} 
hasta hoy, 349 libretos barceloneses publicados entre 1717 y 1808 , con un pico en el número de publicaciones en torno a 1750 , seguido por una caída de las publicaciones primero progresiva y, a partir de 1780, más brusca. Esta caída, sin embargo, no responde a una disminución significativa del número de obras nuevas ni del número de interpretaciones efectivas. Aunque no disponemos de datos exhaustivos, sabemos que, en 1786, año en el que se publicó un único libreto, hubo al menos 49 ejecuciones de oratorios en las iglesias de Barcelona (una por semana de media), siempre en el marco de fiestas de periodicidad anual ${ }^{21}$. En 1807, fueron al menos 34, lo que sugiere que seguían siendo algo muy habitual en la ciudad. Este año, además, hubo 23 interpretaciones excepcionales de los seis oratorios nuevos compuestos para las fiestas de beatificación de Josep Oriol, lo que llevó el total a $57^{22}$. La disminución en el número de libretos publicados no supuso, pues, una disminución significativa en el número de interpretaciones de oratorios, que se mantuvo bastante estable hasta la crisis de 1808 .

La ejecución musical de las siestas tenía lugar por la tarde temprano, en las iglesias, delante del altar mayor o de otros altares secundarios, siempre brillantemente iluminados para la ocasión. Hay que aclarar, no obstante, un malentendido tenaz que ha servido para negar a la siesta del siglo XVIII una dimensión estética en principio ajena a su condición primordial de acto devocional ${ }^{23}$. En la Barcelona del siglo XVIII, las siestas habían perdido cualquier relación específica con la celebración eucarística del Corpus Christi (aunque las de la octava de Corpus seguían siendo particularmente lucidas) y, por tanto, una relación necesaria con los momentos de exposición y reserva del Santísimo Sacramento ${ }^{24}$. El dietario del barón de Maldà, la fuente más importante en relación con estas prácticas,

${ }^{21}$ Ll. Bertran: Musique en lieu..., pp. 190-192.

22 Se puede consultar la tabla publicada en Lluís Bertran: "Oratoris i villancets entre la ciutat i el territori (1715-1808)", Musica i política a l'època de l'arxiduc Carles en el context europeu, Tess Knighton, Ascensión Mazuela (eds.), Barcelona, Ediciones La Central, 2018, pp. 144-147, a la que se deben añadir otros dos oratorios no mencionados por Maldà pero anunciados en $D d B$, el 26 de mayo en la iglesia de Sant Felip Neri y el 1 de diciembre en la Mercè. $D d B$, n. ${ }^{\circ}$ 145, 25-5-1807, p. 635; n. ${ }^{\circ} 334,30-$ 11-1807, p. 1486. La caída del número de publicaciones resulta engañosa y ha llevado a situar demasiado pronto la crisis del oratorio eclesiástico en Barcelona, que no se produjo hasta después de 1808, por ejemplo en Xavier Daufí: "Study on the Decrease in Production of the Oratorio in Catalonia in the Last Decades of the Eighteenth Century and the First Decades of the Nineteenth Century", Revista de Musicología, XXVI, 1-2, 2013, pp. 171-188.

${ }^{23}$ La asociación entre la siesta y la celebración del Corpus se mantiene en Antonio Ezquerro: "Siesta", DMEH, IX, pp. 1004-1007; J. J. Carreras: "El concierto: acto estético y social", La música en España en el siglo XIX..., pp. 135-136; M. Á. Marín: "Escuchar la música...", p. 480.

${ }^{24}$ Entre los motivos más habituales que daban lugar a la ejecución de oratorios, se cuentan las fiestas de las advocaciones de Cristo, la Virgen y los santos más veneradas en la ciudad, además del Santísimo Sacramento, el fin de curso de las instituciones académicas, las profesiones en conventos femeninos, las nuevas beatificaciones y canonizaciones y la consagración de nuevas iglesias y altares. Xavier Daufí: Estudi dels oratoris de Francesc Queralt (1740-1825). Fonaments de la història de l'oratori a Catalunya al segle XVIII, tesis doctoral, Universitat Autònoma de Barcelona, 2001, pp. 93-96. 
suele precisar los casos, excepcionales, en los que el Santísimo seguía expuesto por la tarde ${ }^{25}$. Es más, el obispo José Climent (reg. 1766-1775), al introducir en 1775 la devoción de las Cuarenta Horas, prohibió explícitamente la interpretación de oratorios estando expuesto el Santísimo, "porque semejante musica distrahe à los que desean recogidos meditar, y adorar al Señor [...]: y atrahe à muchos para pasar la tarde entretenidos en oir la musica que les deleyta; y tal vez en hablar con las mugeres sentadas à su lado"26.

Las autoridades episcopales, al atacarla, admitían implícitamente que la siesta musical era también una ocasión para el entretenimiento, el consumo estético y la sociabilidad, elementos que asociaríamos más bien con el concierto profano. El dietario del barón de Maldà permite, a veces, ahondar en la comprensión de esta dimensión estética y social. El 1779, en su minucioso relato las fiestas de beatificación del religioso catalán Miguel de los Santos en la iglesia de los trinitarios descalzos, deja constancia de una práctica de la repetición pedida por un público de "apasionados": "por la tarde [hubo] oratorio nuevo del Beato Miguel de los Santos, el drama se titulaba Josué victorioso de los Amalecitas; todas las arias fueron de delicada música, así como la cavatina de Respire el alma, que por cantarla tan dulce y suave el escolán Joanet Coll, quisieron los apasionados el da capo"27. Cuando Maldà censura la música en el templo, su crítica va dirigida únicamente a situaciones mucho más circunscritas en las que la dimensión teatral adquiere, para él, un relieve excesivo: por ejemplo, una ceremonia litúrgica en la que cantan los operistas del teatro o el uso de una música de lucimiento vocal en la liturgia de un día de recogimiento como es el Miércoles Santo ${ }^{28}$. La animosidad de Maldà, ligada al arraigado prejuicio contra los "cómicos", no afectaba al influjo de la música operística italiana, que él mismo reconocía

\footnotetext{
25 Sobre los oratorios de Corpus, AHCB, Ms. A 202, CdS II, p. 11 (29-5-1785). Para un ejemplo de oratorio ante el Santísimo expuesto, en la iglesia de Sant Pere de les Puel.les, fuera de las celebraciones de Corpus, AHCB, Ms. A 202, CdS II, p. 80 (21-3-1786). Para un ejemplo explícito de siesta sin exposición del Santísimo, AHCB, Ms. A 204, CdS IV, p. 34 (1-2-1789).

${ }^{26}$ Edicto del Ilustrísimo Señor Don Josef Climent obispo de Barcelona, en que hace saber a los feligreses de esta ciudad, haberse instituido en sus Iglesias la oración de las Quarenta Horas, Barcelona, Imprenta de la viuda y herederos de Thomás Piferrer, plaza del Ángel, 1775, pp. 26-27. Maldà se hace eco de quejas muy parecidas en 1783 y, de nuevo, en 1815. AHCB, Ms. A 201, CdS I, p. 297 (30-6-1783); Rafel d'Amat i de Cortada, Baró de Maldà: Calaix de Sastre, XI: 1815-1816, selecció i edició de Ramon Boixareu, Barcelona, Curial, 2003, pp. 16-17 (13-2-1815).

27 "[...] y en la tarde Oratori nou del Beato Miguel de los Santos, el Drama se intitulaba, Josué victoriós dels Amalecitas; totas las arias foren de delicada musica, y la Cabatina de respire el Alma que per cantarla tan dolza, y suau Lo Escolanet Juanet Coll volgueren los Apasionats el Dà Capo". Biblioteca de Catalunya (BC), Ms. 2543, "Solemnes Festas en los dos Convents, y Iglesias de Barna de Pares Trinitaris Descalsos, y Calsats ab lo motiu de la Beatificaciô del Beato Miguel de Los Santos, Natural de la Ciutât de Vich en Cataluña", f. 101v.

${ }^{28}$ AHCB, Ms. A 201, CdS I, p. 249 (7-4-1783); Ms. A 234, CdS XXXIV, p. 219 (25-3-1807).
} 
y asumía tanto en el lenguaje y las formas musicales (la cavatina) como en algunos de los códigos de comportamiento que rodeaban su recepción (la repetición pedida).

Reconocer la siesta como espacio para el disfrute musical de los "apasionados" encaja con el papel capital que, recientemente, se ha venido atribuyendo a los espacios eclesiásticos en la recepción de nuevos repertorios vocales e instrumentales en el siglo XVIII ${ }^{29}$. Tanto o más que la liturgia propiamente dicha, las siestas barcelonesas fueron un ámbito de asimilación de música de autores extranjeros. Es el caso de Joseph Haydn, estudiado por Alier, con la rápida difusión del Stabat Mater (Hob. XXa:1), a partir de 1782, y de las Siete Palabras (Hob. XX:1), a partir de 180130; pero también de otros autores. En la iglesia de los trinitarios calzados, la tarde del 21 de septiembre de 1789 y en el marco de unas rogativas para la prosperidad del reinado de Carlos IV, la capilla de música de la catedral interpretó, en lugar del acostumbrado oratorio de un compositor local, el drama sacro "nuevo" Ester graciosa a los ojos de Asuero, "puesto en música por el Maestro de Capilla Romano Juan Bautista Borghi"’31. También la música instrumental manifiesta una inusitada presencia en este marco, aunque subordinada a la música vocal y a menudo invisibilizada en las fuentes. La estructura ordinaria de una siesta grande implicaba dos sinfonías al menos desde 1763, algo que confirman algunas de las descripciones más minuciosas del barón de Maldà32.

Desde fechas tempranas, Maldà se etiquetaba a sí mismo como "apasionado" de la capilla musical de la catedral de Barcelona ${ }^{33}$ y mostraba cierto menosprecio por las otras capillas musicales de la ciudad, como la de Santa

\footnotetext{
${ }^{29}$ M. Á. Marín: "Joseph Haydn y el Clasicismo vienés...", pp. 485-486 y 491-493. Véase también Javier Garbayo: "Música instrumental y liturgia en las catedrales españolas en tiempos de Barroco", Quintana, 1, 2002, pp. 211-224.

${ }^{30}$ R. Alier: "Notes sobre la música de Haydn a la Barcelona del segle XVIII", Butlletí de la Societat Catalana de Musicologia, 2, 1985, pp. 41-47.

${ }^{31}$ Fiesta solemne y rogativa pública con que se implorará el patrocinio de Maria Santisima, baxo el título de las Mercedes, para alcanzar del todo-poderoso los aciertos del Rey N. S. D. Carlos IV (que Dios guarde), y las prosperidades de la monarquía de España baxo su reynado. Se celebrarán en la Iglesia de PP. Trinitarios Calzados de la Ciudad de Barcelona, en los días 21, 22 y 23 de Septiembre del año de 1789, á expensas de un Devoto de la Virgen, y afecto à su Monarca, Barcelona, Oficina de Carlos Gibert y Tutó, 1789, p. [6]. Podría tratarse del oratorio de Giovanni Battista Borghi Il trionfo di Mardocheo (1774), entre cuyos personajes encontramos también a Ester y Asuero. Escrito para los padres del Oratorio de Roma, el libreto fue reeditado varias veces en Italia y Alemania. Claudio Sartori: I libretti italiani a stampa dalle origini al 1800, Cuneo, Bertoli \& Locatelli, 1992, vol. V, p. 404.

32 J. Pavia i Simó: "Documents per a la història...", pp. 106-108; J. Garbayo: "Música instrumental y liturgia...". Un ejemplo detallado por Maldà, citado más abajo en este trabajo, en AHCB, Ms. A 202, CdS II, p. 371 (3-3-1785).

33 Rafael d'Amat i de Cortada, Baró de Maldà : "Festa major en Esplugas de Sant Mateu apòstol y evangelista succehida en lo any 1779", Miscel-lània de viatges i festes majors, volum I, edició crítica de Margarida Aritzeta, Barcelona, Barcino, 1994, p. 214.
} 
María del Mar o la del Palau de la Comtessa, a la que su amigo Joan Mas atribuía "el negro calificativo de caca" ${ }^{34}$. Gracias a ello, sus textos no solo informan de manera casi exclusiva de las distintas actividades de la capilla de la catedral, sino que perfilan los retratos de otros seguidores incondicionales de ese conjunto musical, entre los que se cuentan los regidores del Ayuntamiento Cayetano Fèlix de Molinas y Rafael de Llinàs, el corredor de cambios Fèlix Cantalosella, el negociante Joan Mas, el oficial de la Administración General del Correo Josep Benet Fernández de Alonso o el capellán Sala. Muchos de ellos son también activos mecenas de la capilla, financiando la actividad musical personalmente o desde sus posiciones en congregaciones y otras instituciones y encargando obras a los mejores músicos de la ciudad ${ }^{35}$. Para Molines, Cantalosella o el propio barón de Maldà, la búsqueda apasionada de la singular combinación de goce espiritual y estético que les proporcionaba la audición de la capilla de música de la catedral, supuso incluso poner en riesgo la economía de sus casas. Es más, como he mostrado en otro lugar, era la financiación externa, obtenida en buena parte del compromiso personal de los "apasionados", tanto o más que las rentas del cabildo, la que contribuía de forma determinante a asegurar el sustento y la buena calidad de la capilla musical de la catedral de Barcelona ${ }^{36}$.

La pasión filarmónica, en la medida en que es individual y particular de cada "apasionado", se traslada también al ámbito doméstico. No solo define el tipo de repertorio practicado en la intimidad del aposento, como en el caso de Maldà, muy apegado a los arreglos de obras de la capilla catedralicia que toca con su violonchelo o su pianoforte ${ }^{37}$. Es también el impulso que guía la organización de sesiones musicales caseras que trasladan la siesta musical propia de la iglesia al ámbito doméstico. Por norma, estas sesiones tienen lugar en torno a una imagen religiosa esculpida o pintada que queda realzada por medio de la iluminación, tal y como se haría ante el altar de una iglesia. Existe, en efecto, un enlace topológico entre la siesta en la iglesia y

34 "[...] sent en ell entusiasme la capella de música de la Seu, que prefereix a les altres, anomenantla la mare i silbant ab lo negre mot de caca a la del Palau". Rafel d’Amat i de Cortada, Baró de Maldà: Calaix de sastre, IV: 1797-1798, selecció i edició de Ramon Boixareu, Barcelona, Curial, 1990, p. 121 (5-12-1798).

${ }^{35}$ Ll. Bertran: Musique en lieu..., pp. 217-226. El testimonio de Maldà sobre Rafael de Llinàs es revelador de como las preferencias musicales de los "apasionados" guiaban la selección de los músicos que tocaban en las distintas iglesias. Al referirse al novenario de Santa Lutgarda en la iglesia del convento de bernardas de Santa Maria de Valldonzella, comenta que la capilla de música de la catedral "novament hà entrat à las funcions en la Iglesia de Valldonsella, à las que anaba la Capella de musica de Santa Maria del már, y al present [la de la catedral] al novenari de Santa Lungarda del que cuyda lo S.r Don Rafel Llinás, així com antes Don Anton Son Pare, que era apasionát à la musica de Santa Maria, y est S. ${ }^{\mathrm{r}}$ [Rafel] à la de la Cathredal, y la mateixa hauria escullit yó à trobarme ab lo encarrech de la Novena de Santa Lungarda". AHCB, Ms. A 206, CdS VI, p. 218 (15-7-1791).

${ }^{36}$ Ll. Bertran: Musique en lieu..., p. 225.

${ }^{37}$ Ibid., pp. 217-218. 
la función musical doméstica que Maldà hace explícito al comparar el pequeño oratorio de su casa, en el que se encontraba, iluminada, la imagen de la Virgen de los Dolores a la que dedica un Stabat Mater el Viernes de Pasión de 1783, con el aspecto de la capilla de la opulenta congregación de la Virgen de los Dolores del convento del Bonsuccés en el día de la misma fiesta $^{38}$. Se han podido documentar hasta 22 sesiones musicales de este tipo en Barcelona entre 1783 y 1807 (véase Apéndice 1), lo que indica que estos conciertos espirituales domésticos fueron un fenómeno bastante extendido en la ciudad, especialmente en tiempo de Cuaresma.

El camino del espacio religioso al espacio doméstico era, en realidad, un camino de ida y vuelta. En enero de 1785, el célebre violinista alemán Michael Esser, de paso por la ciudad, fue invitado a unirse a los aficionados que se juntaban para tocar en las academias periódicas que tenían lugar en casa del notario Ramon Mateu i Smandia (f. 1763-1807). Al llegar la Cuaresma, se trasladaron a algunas iglesias de la ciudad. El 3 de marzo de 1785, tocaron todos en la de la Mercè:

Por la mañana hubo oficio en música y sermón [...]; por la tarde, después de algunos conciertos o sinfonías de delicada música, y más al tocar el violín en ellas el célebre Heser, alemán, se cantó el Stabat de Hayden, entrando a tocar la mayor parte de los concurrentes de las serenatas de Casa Ramon Mateu, y los menos músicos de profesión; estuvo llena la Iglesia de la Mercè mañana y tarde de gente de todas las clases, edades y estamentos con el motivo de esta lucida función ${ }^{39}$.

Aunque "función (funció)" es un término amplio, el uso constante que le da Maldà para referirse tanto a las ceremonias y siestas con música en las iglesias como a los conciertos espirituales caseros, apunta a la identidad entre estos dos fenómenos.

Por otro lado, la afluencia de fieles a la "función" de la Mercè plantea la cuestión del público de esos acontecimientos musicales. Aunque resulta tentador idealizar el acceso gratuito de todos los estamentos al disfrute de la música, muchas de las fiestas financiadas por congregaciones o por particulares revestían una fuerte dimensión comunitaria que aseguraba a sus

38 "[...] intencionàt de fér jó cantàr un Stabat en Casa, per possehir â una Imatge vestida, de la Mare de Deu dels Dolors, [...]; se collocà en lo Oratori, el que se illuminà ab 6 ciris en la Grada, y mesa del Altàr, encesos item los sinch del Salamó de Plata, que semblava ab tants llums en tal puesto reduhit, la illuminació grosa del Altàr de la Capella de la Congregació dels dolors de Maria Santíssima". AHCB, Ms. A 201, CdS I, p. 250 (11-4-1783).

39 "Al dematí hi hagué Ofici en música, y Sermó [...]; en la tarde després de alguns Concerts, o Sinfonias de delicada música, y més sonanthi lo violí lo Cèlebre Heser Alemany, se cantà lo Stabat d'Hayden, entranthi a sonar la major part los Concurrents a las Serenatas de Casa Ramon Mateu, y los menos músics de profesió; estigué plena la Iglesia de la Mercè matí y tarde de Gent de totas Clases, edats, y estaments ab lo motiu de esta lluhida funció". AHCB, Ms. A 202, CdS II, p. 371 (3-3-1785). Véanse también, en el mismo volumen, p. 365 (24-1-1785) y p. 376 (21-3-1785). 
promotores y a sus invitados un lugar preferente y, por lo tanto, unas mejores condiciones de escucha ${ }^{40}$. En la entrada de su dietario del 9 de marzo de 1801 (véase Apéndice 2), Maldà sumerge al lector en la función musical ofrecida aquel día en la iglesia de Jonqueres, cuyo anuncio en el Diario de Barcelona otorga a la música un papel publicitario.

Fiesta. Hoy, a expensas de algunos devotos, en el Real Monasterio de Junqueras, señoras del Hábito de Santiago, habrá una muy tierna función, en que se cantará un nuevo y solemnísimo Miserere, con primorosa música: se empezara a las cinco $^{41}$.

La descripción de Maldà revela, una vez más, el predominio de la dimensión sensible y social de las siestas que mantenía en guardia a las autoridades episcopales. Para financiar la función, cuatro damas profesas de Jonqueres, las dos hijas menores del propio barón de Maldà y dos chicas de Casa Magarola, pidieron dinero a sus "padres, hermanos y demás personas afectas". En justa compensación, estos fueron invitados, junto con otras personas de su entorno, a ocupar los primeros bancos, los más cercanos al tablado donde se colocaron los músicos de la catedral y los aficionados que acudían a las academias que tenían lugar en el piso de las hermanas Codina, en Casa Novell, de las que trataremos más adelante. Baste decir ahora que los principales músicos de la catedral tocaban en estas academias y que tanto los Magarola como el barón de Maldà se contaban entre sus suscriptores. Asisten también algunos de los ya conocidos "apasionados" de la música de la catedral, como Joan Mas, el capellán Sala y, dice el Barón, "algún otro que no recuerdo". La obra estrenada, principal objeto del anuncio en el Diario de Barcelona, ejecutada después de una "escogida sinfonía [...] de Hayden o de Pleyel", es el segundo Miserere del maestro de la catedral de Valencia, Josep Pons, al que Maldà llama, en otra ocasión, "el Hayden catalán”+2. Una vez más, la devoción no excluye el éxtasis del melómano: "[la] unión [de las voces] y de los instrumentos era gran melodía en los pasajes del Miserere en los tonos de tercera mayor y tercera menor, que ha empezado así, suave y pizzicato, como música fúnebre". Respecto al Miserere de Pons, Maldà deja constancia de una práctica de la exclusividad que resulta característica de las lógicas de mecenazgo musical del Antiguo Régimen. Se trata de un regalo ofrecido por el compositor a Doña Francisca Benages, quien, "al dejarlo para cantar, lo entregó en mano a su confidente [...] Francisco Mas”, uno de los

\footnotetext{
${ }^{40}$ La invitación era preceptiva en el caso de las ceremonias de profesión en conventos. Ll. Bertran: Musique en lieu..., pp. 210-212. Véase también Rosa Maria Creixell Cabeza: Noblesa obliga. Lart de la casa a Barcelona (1730-1760), Perpignan, Presses Universitaires de Perpignan, 2013, pp. 177-179.

${ }^{41} \mathrm{DdB}, \mathrm{n} .{ }^{\circ}$ 68, 9-3-1801, pp. 275-276.

42 "[...] la Salve, escullida musica [...] del Sr. Mestre de Capella de la Cathedral de Valencia, podentse intitulàr lo Hayden Català". AHCB, Ms. A 226, CdS XXVI, p. 231 (4-4-1803).
} 
cantores del estreno, célebre contralto de la catedral y también miembro destacado de las academias de Casa Novell.

En resumen, la siesta musical aparece como un fenómeno con una amplísima implantación en Barcelona durante la segunda mitad del siglo XVIII, en la que, a pesar de su función devocional y de la gratuidad del acceso, se revela también una dimensión mundana ${ }^{43}$. Ocasión para el cultivo de sociabilidades escogidas y para el entretenimiento elitista, la siesta es asimismo un lugar de selección y consumo estéticos orientados por la parcialidad de los "apasionados", la recepción de nuevos repertorios y los usos del mecenazgo aristocrático, rasgos que comparte con los conciertos espirituales que tenían lugar en las casas acomodadas de la ciudad.

\section{Las serenatas y academias}

Al tratar de los conciertos profanos, Maldà utiliza una terminología distinta y más variada. Los términos más habituales son diversión o divertimiento musical (diversió, divertiment de música), serenata, academia, prueba de música (prova de música) y concierto (concert). Diversión o divertimiento parece significar cualquier ocasión destinada a distraer por medio de la música. El término enfatiza el cometido principal que tiene, según Maldà, la música no religiosa, a saber, entretener y disipar los malos humores (mientras que la religiosa suma, a estas mismas virtudes, la de estar consagrada al culto o a la evocación de lo divino), y adopta un valor genérico que se opone al del término función, reservado para acontecimientos más solemnes. Serenata y academia, más específicos, comparten significado: un concierto profano en el espacio doméstico. Sin embargo, para Maldà, la serenata sería el concierto ocasional, que no se repite, con asistencia por invitación y que tiene a menudo una dimensión conmemorativa (una visita importante, un santo o aniversario, una boda, un nacimiento, etc.), mientras que la academia es un evento en una serie periódica, a menudo con asistencia por suscripción ${ }^{44}$. En una ocasión, Maldà opone explícitamente los dos significados. En 1802, al describir un concierto ocasional en Casa Sampera y

${ }^{43}$ En este artículo utilizamos el adjetivo "mundano" con la acepción de algo "perteneciente o relativo al gran mundo" (DRAE), en el sentido del término francés mondain. Para un análisis de las nociones de monde y mondain en la Francia del siglo XVIII, definidas por prácticas de sociabilidad distintivas, cierto confort material y una hospitalidad selectiva, véase Antoine Lilti: Le monde des salons. Sociabilité et mondanité à Paris au XVIII ${ }^{e}$ siècle, s. 1., Fayard, 2005. Para una aproximación a las sociabilidades ritualizadas de la Barcelona del siglo XVIII, véase María de los Ángeles Pérez Samper: "Espacios y prácticas de sociabilidad en el siglo XVIII: tertulias, refrescos y cafés de Barcelona", Cuadernos de Historia Moderna, 26, 2011, pp. 11-55.

${ }^{44}$ El término "serenata" había perdido el sentido cerrado de género musical que tenía en la primera mitad del siglo, pero no el de su función conmemorativa. J. J. Carreras: "La serenata en la corte española (1700-1746)", La serenata tra Seicento e Settecento: musica, poesia, scenotecnica, Nicolò Maccavino (ed.), Reggio Calabria, Laruffa Editore, 2007, vol. 2, pp. 599-626. 
oponerlo a las academias semanales de Casa Novell, Maldà dice que se trataba de una "serenata, pues no [era] academia (serenata, ja que no academia)"45.

A partir de las definiciones que acabamos de dar, el cuadro del Apéndice 1 recoge 16 testimonios de manifestaciones musicales que entrarían dentro de la categoría de serenata y otros 18 de temporadas de academias, algunas de las cuales se extendieron a lo largo de varios años. Entre aquellos que cedieron sus domicilios para la celebración de temporadas de academias encontramos a militares, aristócratas locales, un abogado y numerosos notarios, prósperos comerciantes y un único músico, Josep Prats. Entre las anfitrionas femeninas de la élite social, se cuentan algunas damas de la aristocracia madrileña instaladas temporalmente en Barcelona, como la marquesa deVillescas (en Casa Sessa, en 1779), y otras figuras femeninas relacionadas con el alto funcionariado borbónico. Las mujeres tuvieron asimismo un peso muy importante entre los intérpretes aficionados que participaban en las academias.

Aunque tenemos registradas temporadas de academias en Barcelona desde la década de 1760 (véase Apéndice 1), en el presente artículo nos dedicaremos a las que nacieron en casa del violinista y sacerdote Josep Prats, de las que tenemos una primera noticia en abril de 1789, cuando Maldà ya las presenta como "de las más lucidas" de la ciudad ${ }^{46}$. Josep Prats realizó toda su carrera en la catedral de Barcelona. Entró en la institución como escolán y siguió en la capilla tras perder la voz en $1764^{47}$. En 1785, al fallecer Josep Capó, le sucedió como primer violín de la capilla, plaza que conservaría hasta su propio fallecimiento en torno a $1805^{48}$. Los conciertos tenían lugar en su casa, primero en la calle del Bou, al lado de la catedral, y luego en un segundo piso en la esquina de las calles Comtal y de les Moles que compartía con su hermano Joan Prats, llamado Pratets, también violinista de la catedral ${ }^{49}$. Lo que empezó sin duda como un entretenimiento informal en el que participaban sus discípulos y otros aficionados cercanos a la capilla de música de la catedral, como el propio barón de

\footnotetext{
${ }^{45}$ AHCB, Ms. A 224, CdS XXIV, p. 260 (25-3-1802).

46 "[...] fentse en Casa sua en los Dimecres de las Semanas de Ivern Academia de musica, y de las mes lluhidas". AHCB, Ms. A 204, CdS IV, p. 105 ([7-4]-1789).

${ }^{47}$ Josep Pavia i Simó: "La capella de música de la Seu de Barcelona en el segle XVIII (1756-1765)", Anuario Musical, 60, 2005, pp. 91-92.

${ }^{48}$ Sobre la muerte de Capó, AHCB, Ms. A 201, CdS I, pp. 383 y 384 (17-4 y 19-4-1785). No conocemos aún la fecha exacta del fallecimiento de Prats, pero consta que tuvo una apoplejía que lo dejó inhábil para tocar en 1804 y que en 1807 ya había fallecido. Rafael d'Amat i de Cortada, Baró de Maldà: Calaix de sastre, VII: 1804-1807, selecció i edició de Ramon Boixareu, Barcelona, Curial, 1987, pp. 53 y 86.

49 Sobre la primera dirección y los comienzos informales de las academias, AHCB, Ms. A 234, CdS XXXIV, p. 394 (29-5-1807). La segunda dirección, en AHCB, Ms. A 215, CdS XV, p. 524 (9-11-1797), precisada en Rafael d'Amat i de Cortada, Baró de Maldà: Calaix de sastre, VI: 1802-1803, selecció i edició de Ramon Boixareu, Barcelona, Curial, 1994, p. 173 (16-1-1803).
} 
Maldà, fue adquiriendo un grado cada vez mayor de organización interna y un calendario fijo.

Estas academias durarían quince años, desde la temporada 1788-1789 hasta la de 1802-1803, con dos traslados en busca de espacios mayores debido al aumento del público, el primero a casa del notario Manuel Comelles i Aparici (fl. 1765-1808), al comenzar la temporada 1797-1798, y el segundo, al empezar la de 1800-1801, a Casa Novell, en el piso de las dos señoras Codina, hermanas del fiscal de la Cámara de Castilla Domingo Codina $(f l .1769-1811)^{50}$. Los problemas ocasionados por la afluencia creciente de público obligaron también a mejorar la organización. Durante la temporada 1792-1793, las academias funcionaban con una suscripción mensual de 2 durillos (poco más de 42 reales de vellón) ${ }^{51}$. Este sistema por asociación era distinto al funcionamiento por invitación que regía otros momentos del ceremonial aristocrático, como las funciones musicales privadas del barón de Maldà 52 . En 1798 se empezaron a repartir "papeles" entre los suscriptores y, en la temporada 1802-1803, consta que eran cuatro las tarjetas que se daban a cada suscriptor ${ }^{53}$. Pronto ese conato de institucionalización se extendería a la designación informal de dos directores, Joan de Sentmenat i de Clariana, llamado Joanet Clariana o Múnter, hermano pequeño del marqués de Sentmenat, y Francisco Mas, contralto de la catedral, así como de un copista de música, Agustí Panyó, contrabajista de la catedral ${ }^{54}$. Clariana, gran aficionado a la ópera y coleccionista de música, a pesar de un carácter difícil, tenía mucha capacidad de iniciativa en el ámbito musical. Tuvo un papel clave en el estreno de La Creación de Haydn en Barcelona, como veremos. Más adelante, también será el impulsor de temporadas de academias más modestas en Casa Puget en 1806 y en Casa Castellbell en $1807^{55}$.

\footnotetext{
${ }^{50}$ Estos cambios de dirección ya habían sido señalados. J. Carrera i Pujal: La Barcelona del segle XVIII..., vol. 2, pp. 450-453; Josep Maria Mangado Artigas: "Fernando Sor: aportaciones biográficas", Estudios sobre Fernando Sor. Sor Studies, Luis Gásser (ed.), Madrid, ICCMU, 2003, p. 22. Las fechas de actividad de Manuel Comelles provienen de Lluïsa Casas i Loscos: Inventari de l'Arxiu Històric de Protocols de Barcelona, 6. Segle XVIII, 1751-1800, Barcelona, Fundació Noguera, 2009, p. 154. Sobre la actividad de Domingo Codina, Pere Molas Ribalta: “Aragón' en el Consejo de Castilla”, Cuadernos Dieciochescos, 2, 2001, p. 27; id.: "Los fiscales de la Cámara de Castilla", Cuadernos de Historia Moderna, 14, 1993, p. 27.

51 "En lo primer Dimecres de est més de Novembre 7 se comensaren las lluhidas academias de musica de Musichs, y Aficionats, arregladas en los Dimecres de la Semana fins à Pasqua Florida, ò mes allà en Casa del Capellà, Primer Violi de la Capella de musica de la Cathedral ab la Contribució pecuniaria mensual de dos durillos los S.rs abonats Esta academia de musica se comensa à 8 horas de la nit fins à las 10". AHCB, Ms. A 207, CdS VII, p. 510 (28-10-1792).

52 Sobre la distinción entre concierto privado (por invitación) y la academia (por contribución), remitimos a M. Á. Marín: "Escuchar la música...", pp. 462-474.

${ }^{53}$ AHCB, Ms. A 216, CdS XVI, p. 206 (22-3-1798); Ms. A 225, CdS XXV, p. 687 (9-12-1802).

${ }^{54}$ AHCB, Ms. A 225, CdS XXV, p. 687 (9-12-1802); Ms. A 226, pp. 195-196 (24-3-1803).

${ }^{55}$ AHCB, Ms. A 232, CdS XXXII, pp. 266-267 (21-3-1806); AHCB, Ms. A 234, CdS XXXIV, p. 152 (26-2-1807).
} 
Como en las siestas, no había aquí ninguna expectativa de beneficio económico por parte de sus impulsores. El objetivo principal era cubrir gastos y repartirlos equitativamente entre los asistentes, como señalaban los organizadores de las frustradas academias madrileñas de $1799^{56}$. La Biblioteca de Catalunya conserva un interesante documento procedente del archivo del noble Ferran de Sagarra que contiene una propuesta destinada a los "Señores de buen gusto" para la organización de una serie de academias una vez por semana durante la Cuaresma, además del Sábado Santo, en el salón de la casa del marqués de Capmany, Mariano de Sabater (véase Apéndice 3). El documento no tiene lugar ni fecha, pero se puede situar con seguridad en Girona durante los años inmediatamente posteriores a la guerra contra Napoleón. En 1822, el hijo del marqués de Capmany pedía en préstamo el contrabajo del cabildo de la catedral de Girona para poder usarlo en las academias cuaresmales que tenían lugar en casa de su padre ${ }^{57}$. Entre los suscriptores, muchos llevan apellidos locales o tuvieron, en los años posteriores a la guerra, alguna relación con Girona. Además de detallar la duración de los conciertos (de siete a diez de la noche), los programas ("simfonías, conciertos obligados de varios instrumentos, ÿ piezas de canto de las mas modernas”), el número de piezas por concierto (ocho), el de instrumentistas (22 sin contar los cantores) y el nombre de los directores, Antoni Guix [Guiu], organista de la catedral, y Miquel Massip, organista del convento de Sant Daniel ${ }^{58}$, el documento presenta de manera muy clara el funcionamiento de la asociación. Cada suscriptor pagaría 8 reales de vellón por academia y recibiría, a cambio, cuatro tarjetas, una para él y tres para repartir ${ }^{59}$. La solidaridad estamental se manifiesta, en este caso, con la petición de que cada suscriptor preste cuatro sillas para toda la temporada. Asimismo, se garantiza a los suscriptores la elaboración de un estado de los gastos al terminar la temporada. Se establece un mínimo de 50 suscriptores, es decir, unos 200 asistentes. Aunque en el documento conservado solo constan 17 suscriptores, sabemos ya que, en 1822, sí hubo academias cuaresmales en Casa Capmany.

56 “[...] hace mucho tiempo en la calle de San Onofre y casa de Mr. Le Font, músico de la Real Capilla se tenían en los lunes estas academias a que asistían muchos de los actuales suscriptores y otras personas que por los gastos que ocasionaban a Le Font, y no convenirse este a recibir su importe, acordaron buscar un cuarto y subscribirse para los costos del alumbrado, Música y demás que se ofreciesen". Francisco José León Tello, M. ${ }^{a}$ Virginia Sanz Sanz: "La música en la sociedad madrileña del siglo XVIII: documentos sobre una frustrada Academia", Academia. Boletín de la Real Academia de Bellas Artes de San Fernando, 51, 2..$^{\circ}$ semestre de 1980, p. 120.

${ }^{57}$ Montiel Galdon i Arrué: La música a la catedral de Girona durant la primera meitat del segle XIX, tesis doctoral, Universitat Autònoma de Barcelona, 2003, vol. 1, pp. 184-185, 234. (http://hdl.handle.net/10803/5192, 24-6-2018)

${ }^{58}$ M. Galdon i Arrué: La música a la catedral de Girona..., vol. 1, p. 52 y vol. 2, pp. 354-385, passim.

${ }^{59}$ Los redactores se reservaban, sin embargo, la posibilidad de alterar el precio de la suscripción en función del monto de los gastos de las dos primeras academias. 
Todo indica que las academias barcelonesas de antes de la guerra debían de funcionar de forma análoga. Al dividir los dos durillos de la suscripción mensual de las academias de Casa Prats por una media de 4,5 conciertos semanales por mes, el precio por sesión se acerca bastante al de Casa Capmany, quedando en 9,39 reales de vellón. En Barcelona, los conciertos domésticos también tenían lugar por la noche. Las academias solían empezar a las ocho de la noche y duraban, por lo general, dos horas ${ }^{60}$. En realidad, existía una estrecha vinculación entre la temporada de academias y las variaciones anuales en las horas de luz y en la temperatura. En mayo 1801, por ejemplo, Maldà señala que se concluye la temporada de academias por "ya ser cortas las veladas", es decir, porque el sol se pone más tarde, y porque el calor resultante de la iluminación artificial y de la reunión de tantas personas en un espacio cerrado empieza a resultar molesto ${ }^{61}$. Lo habitual, en efecto, era que las temporadas de academias empezaran en noviembre o diciembre y que duraran hasta pasado el domingo de Pascua, es decir, hasta finales de abril o principios de mayo. Estos meses son el negativo exacto de los meses que las personas acomodadas dedicaban a la villeggiatura, estancias a veces muy prolongadas fuera de la ciudad que tenían lugar en los meses de buen tiempo, entre mayo y octubre ${ }^{62}$. Además, la temporada de academias quedaba interrumpida un mes durante el Carnaval, periodo de bailes y saraos, y se retomaba después del Miércoles de Ceniza. Entera, comprendía, con la interrupción del Carnaval, una veintena de conciertos de periodicidad semanal. Algunas veces, las menos, se reducía únicamente al periodo de cuaresma, caso de las academias gerundenses que acabamos de comentar o de las barcelonesas de Casa Rocafort (1798) o de Casa Guitart (1800). En los casos reseñados por Maldà, los últimos días de Cuaresma o entrada ya la Semana Santa, los conciertos adoptaban el tono sombrío de las siestas eclesiásticas de aquellos días. Se convertían en "funciones", en conciertos espirituales dedicados principalmente a la interpretación de Stabat Mater y de otras piezas propias de aquel periodo del calendario religioso. El fenómeno de la función doméstica, explicado más arriba, quedaba así incorporado a la temporada de academias.

Durante años, en realidad, el barón de Maldà, al tratar de las academias, solo da detalles de las funciones, justamente de aquellos conciertos que casaban mejor con su apasionado gusto por las siestas musicales. Las menciones

60 "Esta academia de musica se comensa à 8 horas de la nit fins à las 10". AHCB, Ms. A 207, CdS VII, p. 510 (28-11-1792). También, entre otros casos, AHCB, Ms. A 222, CdS XXII, p. 171 (22-2-1801).

${ }_{61}$ "Esta nit, se han conclosas las Academias de musica en casa Novell, y en efecte, yá son curtas las vetlladas, y la calor en tals concurrencias, y llums, comensa á ferse sensible [...]". AHCB, Ms. A 222, CdS XXII, p. 391 (22-4-1801).

${ }^{62}$ Sobre la villeggiatura y la actividad musical que generaba, Ll. Bertran: Musique en lieu..., pp. $67-$ 79 y $105-143$, passim. 
a los repertorios profanos que llenaban las demás sesiones son muy escasas hasta enero de 1797, alcanzada ya la octava temporada de las academias en Casa Prats. Fuera de los últimos días de Cuaresma, sin embargo, las academias acogían conciertos profanos de tipo misceláneo, con la acostumbrada mezcla de música instrumental con arias y concertantes de las óperas italianas a la moda ${ }^{63}$. Así, en las temporadas de academias convivían repertorios contrapuestos (religioso y profano), pero también músicos de muy distintos orígenes y estatus sociales (instrumentistas y cantantes eclesiásticos, cantantes teatrales y aficionados) y de públicos con actitudes y preferencias no siempre convergentes. Todo ello convertía el concierto doméstico en el lugar de una negociación permanente y no exenta de conflictos.

La consolidación de las temporadas de conciertos domésticos dentro de la oferta de ocio de Barcelona durante la segunda mitad del siglo XVIII acabó atribuyendo al término "academia" un uso local que servía para designarlas. La necesidad de repartir los gastos acarreados por los conciertos llevó a la aparición de un funcionamiento por suscripción similar a los que se han podido documentar en Madrid o Cádiz ${ }^{64}$. La temporada se ordenaba en íntima relación con el calendario religioso y con la organización cíclica del ocio de las élites e integraba, en una serie periódica, el modelo de la serenata y el de la función, prescriptiva en el último periodo de la Cuaresma.

\section{Los conciertos públicos}

El término "concierto (concert)", para Maldà, mantiene largo tiempo las acepciones tradicionales con las que se refiere una composición instrumental o un grupo de músicos ${ }^{65}$. Solo tardíamente empieza a utilizarlo para referirse al acontecimiento en sí, en el sentido moderno, y, cuando lo hace, es únicamente para designar los conciertos públicos por abono o por

63 "[...] per la multitut de àrias que se ouhen, com també la de Quartetos y Quintetos; per las primorosas Sinfonias, obras dels primers mestres de la Europa [...]”. AHCB, Ms. A 222, CdS XXII, pp. $206-$ 210 (5-3-1801). Véase también J. J. Carreras: "El legado ilustrado del concierto...", p. 315.

${ }^{64}$ F. J. León Tello, M. V. Sanz Sanz: "La música en la sociedad madrileña..."; J. J. Carreras: "El legado ilustrado del concierto...", pp. 311-312.

65 Es la segunda acepción, aún dominante en la definición de Jean-Jacques Rousseau seguida por Terreros en 1786 ("Junta, ó multitúd de músicos que cantan, ó tocan instrumentos"), la que habría derivado hacia el sentido actual de evento, que no aparece en el Diccionario de la Real Academia Española hasta 1852 ("Función de música en que se ejecutan composiciones sueltas"), algo que casa con la evolución dibujada por Josep Martínez. Jean-Jacques Rousseau, Dictionnaire de musique, París, Chez la Veuve Duchesne, 1768, p. 111; Esteban de Terreros y Pando, Diccionario castellano con las voces de ciencias y artes y sus correspondientes en las tres lenguas francesa, latina e italiana [...]. Tomo primero, Madrid, Viuda de Ibarra, 1786, p. 481; Diccionario de la lengua castellana por la Real Academia Española, Madrid, Imprenta Nacional, 1852, p. 175; Josep Martínez Reinoso: El surgimiento del concierto público en Madrid (1767-1808), tesis doctoral, Universidad de La Rioja, 2017, pp. 26-29. (https://dialnet.unirioja.es/servlet/tesis?codigo=122696, consulta 24-9-2018). 
entrada en el teatro o en otros espacios de la ciudad, apropiándose sin duda del término utilizado en la mayoría de los anuncios de este tipo de eventos que aparecen en el Diario de Barcelona a partir de $1792^{66}$. Antes de esta fecha, este uso de la palabra parece no formar parte del repertorio de Maldà, puesto que, para referirse a los conciertos del matrimonio Baber en la sala de los veleros en 1789, utiliza el término catalán "prova", prueba, que habitualmente significaba ensayo ${ }^{67}$.

El Apéndice 1 recoge la primera lista sistemática de los conciertos públicos ofrecidos en Barcelona desde su aparición en la ciudad hasta $1808^{68}$. Además del teatro, usado puntualmente como espacio para conciertos, con la orquesta colocada en un tablado encima el escenario y este adornado "con la posible decencia", como reza un anuncio de 1807, también se usó la sala del gremio de veleros de seda (sala dels velers), en las calle de les voltes de Jonqueres (al menos en 10 ocasiones), el gran salón gótico del Palau, que empezó a usarse en 1797, después de la muerte de su propietario, el duque de Alba (hasta en 7 ocasiones) y, una sola vez, en 1790, la sala del gremio de revendedores (revenedors) en la plaza del $\mathrm{Pi}^{69}$. El uso del salón del Palau tendría continuidad en la inmediata posguerra con los conciertos benéficos de 1815, destinados a financiar los grandes funerales de los barceloneses asesinados por los franceses en 1809, y con los conciertos cuaresmales de $1818^{70}$.

Desde 1783, tenemos constancia de forma puntual, aunque con cierta regularidad, de "academias" en el teatro ofrecidas por los miembros de la compañía italiana durante la temporada cómica ${ }^{71}$. En este marco, por influencia del uso italiano, el término adquiere un valor distinto al que le da el barón de Maldà: el de un concierto ocasional, bien como parte de una

${ }^{66}$ El primer caso de uso del término concert en el sentido moderno por parte de Maldà aparece, justamente, en una entrada del dietario que traduce casi literalmente el aviso publicado en el Diario de Barcelona del mismo día: "Avui hà estàt lo trecér concert de arpa executát per lo Profesor Don Gaspar Breidembach à les 8 de la nit en la mateixa Sala de la Confraria dels Velers". AHCB, Ms. A 208, CdS VIII, p. 302 (28-5-1793). Cf. DdB, n. ${ }^{\circ} 148,25-5-1793$, p. 620.

67 "[...] y se fan ab estos dos, ab orquesta plena en la Sala dels velers en algunas nits probas de concerts, y quartetos de esquisita musica". AHCB, Ms. A 204, CdS IV, p. 203 (5-9-1789).

68 Salvo los conciertos ofrecidos a la familia real en 1802, para los que existen buenas descripciones, no hemos tenido en cuenta los espectáculos al aire libre, que merecerían un estudio aparte. Alier sí los consideró en R. Alier: "Els primers concerts públics...", pp. 48-49.

${ }^{69}$ El Palau, llamado también Palau de la Comtessa o Palau Reial Menor, fue demolido en el siglo XIX. Las salas de los veleros y de los revendedores, en cambio, existen todavía en un estado muy cercano al de la época, la primera con entrada por la calle Sant Pere més alt, n. ${ }^{\circ} 1$; la segunda por la plaza del Pi, n. ${ }^{\circ} 3$.

${ }^{70}$ R. d'Amat i de Cortada: Calaix de Sastre, XI: 1815-1816..., pp. 43 y 45 (18-5 y 3-6-1815); R. Alier: "Els primers concerts públics...", p. 48; Francesc Bonastre, M. Dolors Millet: Catàleg del fons Ricart Matas. Reial Acadèmia de Belles Arts de Sant Jordi. I. Programes de concerts públics de Barcelona (17971900), Barcelona, Reial Acadèmia de Belles Arts de Sant Jordi, 2015, pp. $89-90$ (https://www.racba.org/ es/publi_cataleg.php?all=1, consulta 24-6-2018).

${ }^{71}$ R. Alier: L'òpera a Barcelona..., pp. 345, 352, 360, 402, 405 y 411. 
sesión teatral compartida con las otras compañías (teatro español y baile), bien ocupando toda la sesión entera ${ }^{72}$. Estos formatos fueron también adoptados en algunas de las funciones a beneficio de cantantes o instrumentistas de la compañía italiana o de la orquesta del teatro, un fenómeno en aumento a partir de $1790^{73}$.

Sobre conciertos ofrecidos por instrumentistas no tenemos noticias hasta 1788. En el Arxiu Històric de la Ciutat de Barcelona, en la sección "Diversiones públicas" del fondo del Ayuntamiento Borbónico, se conserva un documento relacionado con la temporada cuaresmal del teatro de 1788 en el que se hacen constar las obligaciones económicas para con el Ayuntamiento tanto de la compañía de volatines como del violinista Antonio Ronzi, quien ofreció aquel año los dos primeros conciertos de los que tenemos noticia en el teatro de la ciudad (instalado entonces en una sala provisional debido al grave incendio de 1787). El encabezamiento manuscrito del documento, "sirve de exemplar", sugiere que, quizá ante la novedad de los conciertos cuaresmales de aquel año, los comisarios del teatro nombrados por el Ayuntamiento, entre los que se contaba entonces el regidor y músico aficionado Cayetano de Gispert, establecían con aquel documento un precedente a seguir para futuras ocasiones (véase Apéndice 3).

El desarrollo de los conciertos cuaresmales en Madrid a partir de 1787 tuvo una incidencia directa en la oferta barcelonesa. La costumbre de los virtuosos extranjeros de parar en las principales etapas de su viaje de camino hacia Madrid (o Lisboa) dinamizó también la vida concertística en Barcelona, a la vez que condicionaba su calendario ${ }^{74}$. Sin embargo, Michael Esser visitó Barcelona en 1785, casi tres años antes de su debut en los conciertos cuaresmales del madrileño Teatro de los Caños del Peral. Sí podemos relacionar con los viajes hacia o desde Madrid las visitas de Antonio Ronzi (1788), del matrimonio Baber (o Bauer, 1789), de Gaspar Breidembach (o Breidenbach, 1793), de MarianaVingi ("que pasa á la Corte por primera Bufa de las Operas” en 1797), de Luigia Gerbini (1798), de Maria Antonia Bocucci (1798), del matrimonio Borghese (1800) o de Sophie Gail (1802) ${ }^{75}$. Más singular es el caso de los hermanos trompistas Petrides, estudiado por José Reche, puesto que trabajaron durante cuatro años en el teatro de Barcelona antes de su

${ }^{72} \mathrm{DdB}, \mathrm{n}^{\circ}{ }^{\circ} 206,25-7-1794$, p. 834 (un concierto integrado en una sesión teatral más larga); $D d B$, n. ${ }^{\circ} 277,4-10-1806$, p. 1243 (un concierto ocupando toda la sesión).

${ }^{73}$ R. Alier: Lòpera a Barcelona..., p. 405. Aunque no hemos hecho un seguimiento exhaustivo de este fenómeno, ofrecemos algunos datos en el Apéndice 1. Uno de los conciertos misceláneos de la temporada cuaresmal de 1807 fue a beneficio de Giuseppe Fenzi, violista de la orquesta del teatro, mientras que, en 1803, una función a beneficio del bailarín Leopoldo Banchelli había incorporado un breve concierto misceláneo. $D d B$, n. $^{\circ} 71,12-3-1807$, p. 316; DdB, n. ${ }^{\circ} 230,18-8-1803$, p. 1064.

${ }^{74} \mathrm{~J}$. Martínez Reinoso: El surgimiento del concierto público..., pp. 83 y 84.

${ }^{75}$ Ibid., pp. 82, 222 y 223, passim; M. Á. Marín: "Escuchar la música...", p. 483. 
breve paso por Madrid en $1799^{76}$. En dos casos, los músicos se dirigen explícitamente hacia Lisboa: Giuseppa Rinaldi y Chiara Finetti ("de paso para Lisboa y Londres", 1802) y Antonio Palmini y su hija Orsola (1803)77. Por lo general, los programas de los conciertos ofrecidos por estos virtuosos de paso siguen el modelo europeo dominante en la segunda mitad del siglo XVIII, el del concierto misceláneo, con alternancia de números instrumentales y vocales, que también encontramos en los conciertos madrileños ${ }^{78}$. Sin embargo, no hubo en la ciudad una temporada cuaresmal como las madrileñas hasta 1797 y no fue hasta los últimos años del periodo estudiado, a partir de 1804, cuando este tipo de iniciativa se consolidó bajo el impulso sucesivo de Melchor Ronzi y Antonio Tozzi, dos figuras clave de la etapa más brillante de los conciertos cuaresmales en Madrid ${ }^{79}$.

En unos pocos conciertos ofrecidos en el teatro y para las temporadas cuaresmales, los precios de entrada fueron los mismos que durante la temporada cómica, con entradas y lunetas de platea por media peseta ( $2 \mathrm{rl}$. vn.), que, consecuencia de la inflación de finales de siglo y, tal vez, de un giro en la política teatral por parte de los empresarios, subieron luego a $3 \mathrm{rl}$. vn. (temporada 1801-1802) y a 4 rl. vn. (temporada 1805-1806), acompañando una fuerte subida de los abonos ${ }^{80}$. Los precios, al menos los anteriores a este súbito incremento, permitían la presencia en platea de un público mucho más modesto que los ocupantes de los palcos, simbolizado por aquel apasionado herrero en mangas de camisa retratado por el viajero inglés Arthur Young en $1787^{81}$. Sin embargo, para la enorme mayoría de los conciertos registrados, los precios de entrada fueron muy superiores. Solo en algunas

\footnotetext{
${ }^{76}$ José Reche Antón: Els germans Petrides a Barcelona. Dos trompistes bohemis al Teatre de la Santa Creu (1794-1798), trabajo de final de grado, Escola Superior de Música de Catalunya, 2011. Otros virtuosos de paso, como Giuseppe Calcagni o Alessandro Ferlendis, se instalaron brevemente en la ciudad para ofrecer sus servicios como profesores de música o incluso para conciertos domésticos, caso de un arpista extranjero anónimo que apareció en un intermedio en el teatro en 1796 y que se anunciaba "con otro [profesor] de Guitarra y de Trompa" para "ir à tocar juntos, varias arias variadas en la casa de los señores aficionados que deseen oírlos". Oriol Brugarolas Bonet, Xosé Aviñoa: "Lensenyament musical civil privat a Catalunya entre 1792 i 1838. Noves aportacions al seu estudi”, Educació i Història: Revista d'Història de l'Educació, 32, julio-diciembre 2018, pp. 314, 317 y 318.

${ }_{77}$ Todas las fuentes de estos conciertos se reseñan al final del Apéndice 1.

78 William Weber: La gran transformación en el gusto musical. La programación de conciertos de Haydn a Brahms, traducido del inglés, Buenos Aires, Fondo de Cultura Económica de Argentina, 2011 , pp. 59-69; J. Martínez Reinoso: El surgimiento del concierto público..., pp. 175-183.

${ }^{79} \mathrm{~J}$. Martínez Reinoso: El surgimiento del concierto público..., pp. 95-106, passim.

80 R. Alier: L'òpera a Barcelona..., p. 465; DdB, n. ${ }^{\circ}$ 94, 4-4-1805, "Suplemento", s. p.

81 "In the center of the pit on benches the common people seat themselves. I saw a blacksmith, hot from the anvil, with his shirt sleeves tucked above his elbows, who enjoyed the entertainment equally with the best company in the boxes, and probably much more". Arthur Young: Travels During the Years 1787,1788 , \& 1789; undertaken more particularly with a view of ascertaining the cultivation, wealth, resources, and national prosperity of the Kingdom of France, 2. ${ }^{a}$ ed., Londres, W. Richardson, 1794, vol. 1, p. 41
} 
repeticiones (Breidembach en 1793, Lunati en 1798) o para acceder a las últimas filas de la sala encontramos precios a $4 \mathrm{rl}$. vn. A pesar del número y de la variedad de los promotores, las entradas individuales solían costar entre 2 pesetas $(8 \mathrm{rl}$. vn.) y medio duro (10 rl. vn.), con la única excepción del concierto ofrecido por Sophie Gail, M. Lamotte y Giuseppe Fenzi, que tuvo lugar, significativamente, durante la residencia de la corte en Barcelona y cuya entrada costó $12 \mathrm{rl}$. vn. El baremo de Maldà es ilustrativo. Considera demasiado caros los $8 \mathrm{rl}$. vn. de la entrada del primer concierto de Breidembach en la sala de los veleros en 1793 y los $10 \mathrm{rl}$. vn. de la del concierto instrumental de Joseph Felix en 1801. En ningún caso son precios más altos de lo ordinario para este tipo de eventos, lo que sugiere que los conciertos públicos en Barcelona, especialmente aquellos que tuvieron lugar en salas externas al teatro, fueron eventos para el disfrute de una élite dispuesta a desembolsar entre cuatro y cinco veces el precio de una entrada de platea o de luneta del teatro. Frente a esta opción, las temporadas de academias, aunque tampoco resultaban baratas, tenían la indiscutible ventaja de dar acceso, por el mismo precio por sesión que en un concierto público, al suscriptor y a tres personas escogidas por él y evitarles, además, la mezcla social indiscriminada.

El concierto público fue un fenómeno nuevo en Barcelona en las últimas décadas del siglo XVIII: una diversión musical con un programa anunciado ofrecida por músicos profesionales a un público anónimo mediante el pago de una entrada ${ }^{82}$. La consolidación de los conciertos cuaresmales madrileños favoreció sin duda la presencia ocasional en Barcelona de músicos de paso, facilitando el desarrollo de una oferta concertística en la ciudad y propiciando la organización de temporadas cuaresmales locales, aunque no se hicieron regulares hasta los años inmediatamente anteriores a la invasión francesa. Sin embargo, el alto coste de las entradas, especialmente para los conciertos en salas distintas del teatro, reducía considerablemente el público potencial de estas sesiones, que probablemente acabaría coincidiendo, en una medida aún por determinar, con el de las academias domésticas por suscripción.

\section{Las transformaciones del cambio de siglo y el estreno de La Creación}

La década que va de 1797 a la invasión francesa de 1808 fue testimonio de algunas mutaciones importantes en el paisaje musical urbano ${ }^{83}$. Durante la Cuaresma de 1797, la compañía italiana ofreció, por primera vez, una temporada de conciertos públicos regulares en el teatro. En un primer

\footnotetext{
82 J. Martínez Reinoso: El surgimiento del concierto público..., p. 29. Véase también J. J. Carreras: "El concierto: acto estético...", p. 134.

${ }^{83}$ Precisamos aquí algunos rasgos de una evolución ya esbozada en J. J. Carreras: "El legado ilustrado del concierto...", pp. 314-316.
} 
momento, se interpretaron oratorios no representados, pero se acabaron imponiendo los conciertos misceláneos con números operísticos, mucho más exitosos. Incluso se añadió un último concierto a los quince programados inicialmente ${ }^{84}$. Esta moda parece contagiarse inmediatamente a los conciertos espirituales caseros de aquella Cuaresma. En las funciones de Stabat Mater en Casa Rocafort y en Casa Grancur, en las que participan los músicos de las academias de Casa Prats, se añaden después del Stabat, por primera vez, arias italianas. El tema transciende el círculo de los aficionados y da lugar a un virulento posicionamiento público en el Diario de Barcelona: "Quantas veces, en quantas serenatas, los Stabats sirven de introduccion á las Areas y Orquestas afeminadas, blandas y lascivas? Para quantos el Stabat, hymno dedicado á la Purísima Virgen Dolorida, terminan en cánticos del impúdico himeneo, ó en motetes á la Diosa de la Lascivia?’85. Diez días después, esta opinión resuena en las quejas del barón de Maldà, tan apegado a los conciertos espirituales caseros, quien contrapone la pertinencia de la función de Stabat organizada en casa de Domingo Ruiz, otro de los suscriptores de las academias de Casa Prats, con las realizadas en las casas en las que se mezcla música vocal religiosa y profana:"la función fue muy apropiada y devota por no haberse mezclado con ella lo mundano, es decir, arias amorosas italianas que en otras funciones se hacen entrar después del Stabat, muy inapropiadas $\$$. Con todo, quedaba agrietado el veto a las diversiones musicales en Cuaresma, un hecho que Maldà, después de la ruptura revolucionaria en el país vecino, no dudaba en asociar con la perniciosa alteración de las costumbres y de las mentalidades causada por la influencia francesa ${ }^{87}$.

Aunque existía una Real Orden de 17 de marzo de 1790 que prohibía explícitamente las academias "a escote o por dinero" en Barcelona ${ }^{88}$, estas adquirirían en estos años, especialmente durante la Cuaresma, una relevancia social y pública que no habían tenido hasta entonces. Durante el invierno y, más aún, durante la Cuaresma, cuando el teatro cerraba, los conciertos domésticos acabaron constituyendo uno de los ámbitos de diversión más atractivos para las clases urbanas acomodadas. En marzo de 1798, un año en el que solo hubo dos conciertos cuaresmales públicos en la sala de los veleros, la entrada en las academias de Casa Comelles de los primeros

\footnotetext{
${ }^{84}$ Los cambios en los programas se pueden seguir en los anuncios de DdB. R. Alier: "Els primers concerts públics...", p. 48.

${ }^{85}$ DdB, n. ${ }^{\circ} 82,23-3-1797$, p. 325. Véase también R. Alier: L’òpera a Barcelona..., p. 441.

86 "[...] la Funció molt propia y devota que fou, per no haverhi mesclat lo mundo, vull dir; arias amororsas Italianas, que en altras Funcions fan entrar despues del Stabat de allò ben impropias en altras concurrencias de musica". AHCB, Ms. A 214, CdS XIV, p. 214 (2-4-1797).

${ }^{87}$ Ibid., pp. 213-214.

${ }^{88}$ María Teresa Suero Roca: El teatre representat a Barcelona de 1800 a 1830, Barcelona, Institut del Teatre, 1987, vol. 1, p. 36
} 
nombres de la compañía italiana del teatro, el primo buffo Francesco Albertarelli y la prima buffa Benedetta Marchetti, hizo crecer tanto la concurrencia que se resolvió, como ya se ha dicho, empezar a repartir "papeles" o tarjetas, que en 1802 se habían fijado en cuatro por suscriptor. La boga de las academias llegó a tal punto que, en 1801, se tuvieron sospechas de que se falsificaban tarjetas y se negó la entrada a algunos concurrentes en la puerta misma del piso de las señoras Codina. Maldà se hacía eco de la desazón de muchos suscriptores, "no siendo las academias de música [...] públicas's9. A juzgar por sus quejas constantes, las medidas tomadas por los organizadores no evitaron la entrada masiva de un nuevo público formado por jóvenes y militares que no respetaban la exigencia de silencio que habría imperado hasta entonces y se comportaban de forma desconsiderada ${ }^{90}$. Las constantes llamadas al orden de los propios músicos parecían caer en saco roto. Para Maldà, el aumento de la asistencia y la confusión que generaba había convertido aquellas reuniones en algo "despreciable" ${ }^{\text {"x1 }}$. La suscripción, en este marco, decayó como espacio para las sociabilidades elitistas y exclusivas. A pesar del descontento de los más veteranos, lo cierto es que el modelo de las temporadas de academias por suscripción acabaría muriendo de éxito en Barcelona. En 1803, al transitar, por saturación de sus posibilidades, hacia el formato del concierto público con pago de abono o de entrada, Maldà se declararía, por su parte, "indiferente", contentándose con reproducir las crónicas de los conciertos que le hacían sus hijos ${ }^{92}$.

Del éxito de las academias en estos últimos años del siglo XVIII también da cuenta la aparición de una serie de academias rivales a las de Casa Prats. La primera noticia que tenemos las sitúa en Casa Soler para la temporada 1799-1800. Después (¿O antes?) pasaron a Casa Bacigalupi y, por último, a Casa Oms, en el piso del abogado Puiggarí. En contraposición con las academias que habían nacido en Casa Prats, vinculadas a la capilla musical de la catedral, las de Casa Soler aparecen muy ligadas a la capilla de música de Santa María del Mar. Esta selección trasladaba al ámbito doméstico y mundano los antagonismos existentes entre los "apasionados" de las distintas capillas urbanas que hemos encontrado en el ámbito de las siestas. Durante tres temporadas, las dos sociedades competirían en calidad

89 "[...] decuberts contrafets alguns bitllets, ó targetas, estas dels mes no aprobadas, no sent academias de musica, y demes diversions publicas [...]”. AHCB, Ms. A 222, CdS XXII, p. 103 (4-2-1801). Véase también, en el mismo volumen, p. 203 (4-3-1801).

90 "[...] era una Fantasmagoria la de alguns Fantasmons à no callàr ohint la musica, de estos algun militár, que ab sá llicencia marcial nos cuydaban de que altres estiguesen incomodats, tapant la porta en peus, y pujantsen sobre de las cadiras, per veurer las ninfas, y mes à las agraciadas". AHCB, Ms. A 226, CAS XXVI, p. 164 (12-3-1803).

${ }^{91}$ AHCB, Ms. A 226, CdS XXVI, p. 65 (26-1-1803).

${ }_{92}$ AHCB, Ms. A 227, CdS XXVII, p. 480 (11-11-1803). 
musical de forma cada vez más explícita, hasta convertir esa rivalidad en un tema cotidiano, con el público de cada casa visitando y comparando la calidad musical de las otras academias. Pronto se reconoció la superioridad en la parte instrumental a las de Casa Novell, mientras que las otras serían consideradas mejores en la parte vocal ${ }^{93}$. Por consiguiente, la emulación empuja a Maldà a dar mayor protagonismo al comentario sobre la música instrumental en sus crónicas de las academias en Casa Novell. Así, a lo largo de la última temporada, al referirse a las sinfonías de Haydn que abrían los programas de las academias, deja algunas de las notas más ricas que escribió sobre música instrumental. "Esta noche se ha hecho la cuarta academia de música nuestra en la misma casa, en la calle dels Banys, también con mayor concurso y 3 músicos más de clarinete añadidos para la sinfonía nueva al comienzo, que sé ya tocada, del famoso Hayden, muy dificil, estrepitosa y armoniosa al mismo tiempo $[\ldots . .]^{\prime 94}$.

Comentarios de idéntica naturaleza, siempre referidos a sinfonías de Haydn, aparecen una y otra vez: "de mucha habilidad y dificultad al ejecutarla los músicos", "muy extraña y difícil", "con muchas extrañezas [...] y de gran habilidad en los instrumentos obligados de fagot [y] clarinete", "enrevesada [travessa] con tantas ligaduras y entradas de instrumentos, con mucha armonía en sus salidas [eixidas]" ${ }^{95}$. La presencia de clarinetes podría indicar que se trata de las últimas sinfonías de Haydn, quien no usó clarinetes en el género hasta su sinfonía n. ${ }^{\circ} 99$ (Hob. I:99, de 1793). Todos estos comentarios de Maldà, que tienden a presentar la interpretación de las sinfonías de Haydn como un reto solo al alcance de los mejores instrumentistas de la ciudad ${ }^{96}$, sitúan a su música bajo el signo de lo "extraño" y de lo "difícil", dos términos que el autor reservaba hasta entonces para las obras de música religiosa más complejas u originales ${ }^{97}$. El léxico remite a

${ }_{93}$ AHCB, Ms. A 221, CdS XXI, p. 473 (17-12-1800); Ms. A 222, CdS XXII, p. 169 (21-2-1801); Ms. A 223, CdS XXIII, p. 282 (21-11-1801).

94 "En esta nit se há feta la Quarta Academia de musica nostra en la mateixa casa en lo carrér dels Banys, a mes de major Concurs, y 3 musichs mes de clarinets anyadits per la Sinfonia nova al Principi, que se já tocada del Famós Hayden, molt dificil, estrepitosa, y harmoniosa al mateix temps [...]". Maldà, p. $737(29-12-1802)$

${ }_{95}$ AHCB, Ms. A 226, CdS XXVI, pp. 31 (12-1-1803), 65 (26-1), 83 (3-2), 94 (9-2) y 297 (20-4).

96 "[...] se féu la nostra acadèmia de música escollida, principalment en la Simfonia primera concertant del famós Haydn, i tan difícil per lo entravessada, que a tocar-la altres músics haurien anat de costelles, segons digueren, que els tenia cerca escoltant la música lo Revd. Mestre de capella del Pi i son organista, mossèn Rafel, que tenen vot en la música". Rafel d'Amat i de Cortada, Baró de Maldà: Calaix de sastre, VII: 1804-1807, selecció i edició de Ramon Boixareu, Barcelona, Curial, 1987, p. 180 (3-2-1803).

${ }^{97}$ Por ejemplo, en el caso de una misa oída en el monasterio de Montserrat en 1793: "[...] se ha comensada la solemne misa, [...] cantada que se ha hagut en los Kiries, Gloria, Credo, Sanctus y Agnus Dei, per los escolanets y algun monjo, ab acompañaments de l'orga gran, contrabaix, violas, violins, fugots, etc., que també la música era prou grata als ohidos y un poch estraña y difícil en certs pasos". Rafael d'Amat, Baró de Maldà: Viatge a Maldà i anada a Montserrat, a cura de Margarida Aritzeta, Barcelona, Publicacions de l'Abadia de Montserrat, 1986, p. 156. 
una poética musical propia de la música religiosa, algo que liga perfectamente con la más que notable recepción de Haydn en el ámbito eclesiástico en España ${ }^{98}$ y anticipa algunos de los rasgos que cristalizarían en la acuñación del calificativo peyorativo de "música sabia" durante la primera mitad del siglo XIX ${ }^{99}$.

La temporada 1803-1804 se presenta, en un primer momento, como las anteriores. Se habla de un nuevo lugar para las academias, Casa Puiggarí, y se negocia la participación en ellas de algunos cantantes de la compañía italiana. Pero Joanet Clariana tiene el ambicioso proyecto de estrenar en Barcelona el oratorio La Creación de Haydn, cuyo primer estreno público había tenido lugar en Viena en $1799^{100}$. Hacía más de un año que se hablaba de este estreno, desde que, en abril de 1802, había llegado a la ciudad el primer ejemplar de la partitura. (Se había pensado en estrenarla en la sala del Palau durante la visita real de 1802, pero el proyecto no se realizó.) La obra venía precedida por el aura excepcional de los reconocimientos que había recibido en toda Europa y de los masivos estrenos en Viena, Londres y, sobre todo, París, en el que se sabía que habían tocado 150 o 200 músicos (en realidad fueron 250) ${ }^{101}$. Solo la fama excepcional de que gozaba Haydn, entonces en el punto álgido en intensidad y en extensión, explica al mismo tiempo la publicidad que tuvieron los estrenos en el extranjero y que estos fueran recomendación suficiente para el estreno de la obra en Barcelona ${ }^{102}$.

Para un proyecto de esa importancia, el marco de las academias domésticas se quedaba pequeño. Para lograr su objetivo, Clariana se convirtió improvisadamente en empresario y se unió con un antiguo tenor del teatro, el napolitano Giuseppe Pintauro, activo en las academias rivales de Casa Soler y profesor de música de señoritas en las casas acomodadas de Barcelona ${ }^{103}$, con el que organizó una temporada de academias con pago de abonos y entradas en el gran salón del Palau. La iniciativa era muy original, pues no limitaba los conciertos al habitual periodo de Cuaresma, sino que los extendía a la duración ordinaria de las temporadas de academias domésticas, de noviembre a mayo. Empujada por los requisitos que exigía la

${ }^{98}$ M. Á. Marín: “Joseph Haydn y el Clasicismo vienés...”, pp. 485-486 y 492-494.

${ }^{99}$ J. Etzion: “"Música Sabia': The Reception...", p. 187, passim.

100 AHCB, Ms. A 227, CdS XXVII, p. 497 (15-11-1803).

${ }^{101}$ AHCB, Ms. A 224, CdS XXIV, p. 293 (7-4-1802); Ms. A 227, CdS XXVII, p. 480 (11-11-1803); Ms. A. 228, CdS XXVIII, p. 255 (15-3-1804). Sobre el estreno parisino, Nicholas Temperley: Haydn: The Creation, Cambridge, Cambridge University Press, 1991, p. 41.

102 James Webster: "The Sublime and the Pastoral in The Creation and The Seasons", The Cambridge Companion to Haydn, Caryl Clark (ed.), Cambridge, Cambridge University Press, 2005, pp. 150151. Giuseppe Carpani, en su biografía de Haydn de 1812, indicaba, sin exagerar, que su música se oía "dal Messico a Calcuta, come da Napoli a Londra, da Pera [Constantinopla] a Parigi". Citado en Thomas Tolley: Painting the Cannon's Roar: Music, the Visual Arts and the Rise of an Attentive Public in the Age of Haydn, c. 1750 to c. 1810, Aldershot-Vermont, Ashgate, 2001, p. 20.

103 O. Brugarolas Bonet, X. Aviñoa: "L'ensenyament musical...", pp. 318-319. 
ejecución de aquella "magna obra", como dice Maldà, la práctica restringida de la academia doméstica por suscripción transitaba así hacia el concierto público ${ }^{104}$. Se trata, probablemente, de la primera serie de conciertos públicos fuera de la temporada de Cuaresma en España. Se ofrecieron precios muy competitivos a $5 \mathrm{rl}$. vn., más o menos la mitad de lo que costaba habitualmente acceder a un concierto público, lo que explica, sin duda, su éxito inmediato, a pesar de que no se anunciaron en el Diario de Barcelona. Otra novedad fue que cada entrada individual daba acceso a un asiento numerado ${ }^{105}$.

La primera noche, el 23 de noviembre de 1803, la orquesta reunió a 30 músicos, a los que se añadían los cantantes del teatro, y el público llegó a las 400 personas, cifras que debían prácticamente doblar las de las academias domésticas de la temporada precedente ${ }^{106}$. El éxito parece confirmado por la reacción que suscitó en la dirección del teatro. El empresario, Baltasar de Bacardí, celoso del privilegio exclusivo del teatro en el terreno de las diversiones públicas y temeroso, sin duda, de la competencia que representaban para él los nuevos conciertos, consiguió paralizarlos después de la primera noche ${ }^{107}$. Pero su olfato empresarial le hizo cambiar de opinión y acabó uniéndose a la empresa de Pintauro y Clariana. Los conciertos se reanudaron en el Palau el primero de diciembre ${ }^{108}$. Clariana, sin embargo, seguía decidido a aprovechar la ocasión para el estreno de La Creación. Para los empresarios, más bregados, el riesgo debía parecer excesivo. Siguió una violenta ruptura: Pintauro se desentendió del proyecto, mientras que Francisco Mas, antiguo socio en las academias de Casa Prats, se negó a cantar en el oratorio ${ }^{109}$.

Clariana no desfalleció. Adquirió e hizo venir la partitura desde París, entró en relaciones con el director de las academias poco antes rivales, el maestro de capilla de Santa Maria del Mar, Josep Cau, y organizó por su cuenta, en paralelo con los conciertos en el Palau, el estreno de La Creación de Haydn en la otra sala que se usaba para conciertos, la de los vele$\operatorname{ros}^{110}$. El 15 de marzo hubo un ensayo en la casa de Anton Tusquets, corredor de cambios y antiguo escolán de Santa María del Mar, y otro el día 20 en Casa Sentmenat, residencia del propio Clariana ${ }^{111}$. El estreno

104 Miguel Ángel Marín ha señalado, en relación con el concierto público, que "la mayor disponibilidad de espacio y de presupuesto permitía programar un repertorio también distinto". M. Á. Marín: "Escuchar la música...", p. 474.

${ }^{105}$ AHCB, Ms. A 227, CdS XXVII, pp. 529-531 (23-11-1803).

106 AHCB, Ms. A 227, CdS XXVII, pp. $529-531$ (23-11-1803). Véase también J. J. Carreras: "El legado ilustrado del concierto...", pp. 315-316.

${ }_{107}$ AHCB, Ms. A 227, CdS XXVII, p. 542 (26-11-1803).

108 AHCB, Ms. A 227, CdS XXVII, p. 566 (1-12-1803).

${ }^{109}$ AHCB, Ms. A 228, CdS XXVIII, p. 255 (15-3-1804).

110 AHCB, Ms. A 228, CdS XXVIII, pp. 255-257 (15-3-1804).

${ }^{111}$ AHCB, Ms. A 228, CdS XXVIII, pp. 275-277 (20-3-1804). 
tuvo lugar finalmente el 21 de marzo de 1804, de ocho a diez menos cuarto de la noche (1h 45 de duración ${ }^{112}$ ), con 36 músicos, y cantores eclesiásticos de la catedral, de Santa María del Mar y del Palau en las partes solistas $^{113}$. El anuncio del estreno en el Diario de Barcelona, transcrito por Juan José Carreras, pone de nuevo el énfasis en la dificultad, esta vez logística e idiomática:"esperanzados [...] que disimularán las faltas que hubiese, ya por no ser el idioma natural, como por la falta de instrumentos que no se hallan en esta ciudad [...]"114. Es muy probable que para el estreno barcelonés se arreglaran las partes agudas de Gabriel y de Eva para cantores masculinos adultos, puesto que, al terminar la primera ejecución, Cau prometió formar a dos de sus mejores escolanes para cantar esas partes vocales ${ }^{115}$. Por Maldà sabemos que hubo dos contrabajos, además de violonchelos y violines (y violas), timbales, clarines, trompas, fagotes, clarinetes y flautas. Entre los instrumentos que faltaron, estuvieron los tres trombones y el contrafagot presentes en la edición parisina de Pleyel de 1801. Tratándose de esta edición, que llevaba un texto bilingüe en francés e italiano, la obra se cantó probablemente en italiano, un idioma probablemente más familiar que el francés para la mayoría de músicos, aunque fueran eclesiásticos. A pesar de las muchas dificultades de la obra, el éxito fue rotundo: aquella misma noche se habló ya de repetirlo y, de hecho, se repetiría dos veces más "a solicitud de muchos aficionados", como reza el Diario de Barcelona ${ }^{116}$.

Giuseppe Pintauro, sorprendido por este sonoro éxito, se vio impelido a organizar otra interpretación de La Creación por su cuenta, esta vez con los operistas italianos. Las rivalidades previas entre las dos asociaciones de academias emergen de nuevo, pero revisten ahora nuevos tintes identitarios, según Maldà, entre "los [...] musichs Cantors, y Instrumentistas Catalans", ligados a las capillas eclesiásticas de la ciudad, y "los Cantores Italians del teatro", aunque, con toda seguridad, buena parte de los instrumentistas fueron los mismos ${ }^{117}$. Las condiciones de este debate identitario sobre los méritos respectivos de los músicos italianos y nacionales remiten a otro

\footnotetext{
112 Esta duración coincide con la de la mayoría de grabaciones discográficas actuales de la obra.

113 Anton Cassanyes, chantre del Palau, Maginet y Joan Vinyals, respectivamente tenor y contralto de la catedral, y Josep Sauri, tenor de Santa Maria del Mar. AHCB, Ms. A 228, CdS XXVIII, pp. 256 (15$3-1804)$ y $278-281(21-3)$.

${ }^{114}$ DdB, n. ${ }^{\circ} 81,21-3-1804$, p. 364. J. J. Carreras: "La recepción de la música alemana...", p. 333.

115 AHCB, Ms. A 228, CdS XXVIII, p. 281 (21-3-1804). Desde el primer momento, se era consciente de la dificultad de disponer de un tiple vocal capaz de enfrentarse con éxito a las partes solistas de la obra. AHCB, Ms. A 224, CdS XXIV, p. 293 (7-4-1802).

${ }^{116} D d B,{ }^{\circ}{ }^{\circ} 97,6-4-1804$, p. 444; $D d B$, n. ${ }^{\circ} 99,8-4-1804$, p. 452. Un cuarto concierto, previsto el 25 de abril, se acabará suspendiendo "por indisposición de algunos Profesores". DdB, n. ${ }^{\circ} 115,24-4-$ 1804 , p. $528 ; D d B$, n. $^{\circ} 116,25-4-1804$, p. 536.

${ }_{117}$ AHCB, Ms. A 228, CdS XXVIII, p. 488 (15-5-1804).
} 
que había tenido lugar 15 años antes en Madrid en torno a los conciertos cuaresmales ofrecidos simultáneamente por las dos compañías de cantantes italianos y españoles ${ }^{118}$. La carta de un lector del Diario de Madrid identificaba esta polémica con "la greguería que se oye en las tertulias"119, reconociendo con ello la dimensión principalmente social de estos debates, más ligados a las sociabilidades de las clases acomodadas que a una contraposición de argumentos sometida al escrutinio de una opinión pública apenas incipiente ${ }^{120}$.

En realidad, gracias a una nota impresa remitida a los suscriptores de sus conciertos en el Palau, que terminaron el 2 de mayo ${ }^{121}$, descubrimos que la iniciativa no fue de Pintauro, o no únicamente suya, sino también de los propios suscriptores, aguijoneados seguramente por el éxito de Clariana:

Deseoso Don Joseph Pintauro de corresponder agradecido à la solicitud, que los Señores Subscriptores de su Concierto han manifestado, para que se exêcutase baxo su direccion el celebrado Oratorio de Haydn: tiene la particular satisfacion de prevenirle, que se está preparando, con la posible brevedad, y que no omitirá diligencia, ni cuidado; para que salga con toda la expresion que exîge esta obra, acompañada de todas las circunstancias, que fueren dables para su exâctitud ${ }^{122}$.

En un anuncio posterior en el Diario de Barcelona, en el que se informaba del estreno en dos noches, en una con las partes primera y segunda del oratorio y en la otra con las partes primera y tercera, Pintauro se refería de nuevo a las dificultades que suponía su ejecución, poniendo énfasis en "los muchos cuidados que le han costado para dignamente poder llevar á efecto su intento, no obstante las muchas y casi insuperables dificultades que se han opuesto al exito de tan peligrosa empresa"123. Pintauro compró otro ejemplar de la partitura editada por Pleyel en París. Publicó, asimismo, un libreto con el texto italiano de la edición de Pleyel (excusándose por la mala calidad de la traducción), que dedicó al intendente y futuro afrancesado Blas de Aranza (1753-1813), “nombrándolo Ilustrísimo Reverendísimo

118 J. Martínez Reinoso: El surgimiento del concierto público..., pp. 191-192, 258.

119 D. M. R. F., "Carta sobre los teatros", Diario de Madrid, n. ${ }^{\circ} 95,5-4-1790$, pp. 377-379; n. ${ }^{\circ} 96$, 6-4-1790, pp. 381-383; n. ${ }^{\circ} 97$, pp. 385-387.

120 Ana Sánchez-Rojo: "Prensa, opinión y música teatral en Madrid, 1780-1791", Cuadernos de Música Iberoamericana, n. ${ }^{\circ}$ 30, enero-diciembre 2017, pp. 23-55.

${ }^{121}$ AHCB, Ms. A 228, CdS XXVIII, pp. 413-414 (2-5-1804).

122 Esta pequeña nota impresa apaisada, de 8 por $11 \mathrm{~cm}$, enmarcada por una sencilla orla de motivos vegetales, apareció en el sitio de venta online Todocolección.net y pudimos copiar el contenido a partir de la foto colgada por el vendedor (24-6-2018).

${ }^{123} \mathrm{DdB}$, n. $^{\circ} 136,15-5-1804$, p. 624. 
Signore, según carácter de los italianos"124. Las lógicas mundanas que presiden esta iniciativa vienen confirmadas por la insistencia en el papel que tuvieron en ella algunos de los suscriptores de la temporada de conciertos del Palau. En la dedicatoria del libreto, Pintauro reconoce, una vez más, el "estímulo de personas respetables y acreditadas" y apela a su amparo para proteger su ejecución de una "peligrosa comparación", una mención apenas velada a las interpretaciones protagonizadas por los músicos eclesiásticos locales en los meses de marzo y abril ${ }^{125}$.

Al parecer, hubo cinco ensayos previos. Los dos conciertos tuvieron lugar el 17 y el 19 de mayo de 1804, aunque hay algunos datos contradictorios, puesto que el estreno estaba previsto inicialmente para el día 12 de mayo y se cambió, con lo que Maldà, seguramente mal informado, supuso que había tenido lugar el $15^{126}$. Participaron en ella 66 músicos, una cifra sin duda modesta en comparación con las de otras capitales europeas, pero excepcional para la Barcelona de la época. Los papeles solistas fueron interpretados por los principales cantantes de la compañía italiana: la "primera bufa absoluta" Camilla Guidi (Gabriel y Eva), el "primer tenor absoluto" Antonio Berini (Uriel) y uno de los dos primeros bufos "de carácter", Michele Cavara (Rafael y Adán) ${ }^{127}$. No sabemos si Pintauro consiguió añadir los instrumentos de viento que debieron faltar la primera vez, aunque sí sabemos que hubo platillos con la percusión. El mismo Pintauro, en prueba del éxito, retomó la obra para los conciertos que organizó, primero en el Palau y después en el teatro, durante la Cuaresma del año siguiente, a los que se añadió el estreno de la primera parte, la dedicada a la primavera, de Las Estaciones [Die Jahreszeiten] (Hob. XXI:3) de Haydn, que se repitió otro día ${ }^{128}$. En total, hubo en Barcelona entre 1804 y 1805 además de las dos

124 "[...] nombrantlo Ill.mo Reverendissimo Signore segons caracter dels Italians". AHCB, Ms. A 228, CdS XXVIII, p. 488 (15-5-1804). Sobre la adquisición de la partitura, AHCB, Ms. A 228, CdS XXVIII, p. 413-414 (2-5-1804). En la Biblioteca Nacional de España (sig. T/25560), se conserva un ejemplar impreso del libreto: La creazione del mondo oratorio sacro tradotto dal francese posto in musica dal celebre signor maestro Don Giuseppe Haydn ed esequito sotto la direzione del signor maestro D. ${ }^{n}$ Giuseppe Pintauro, Barcellona, Nella Stampería di Giouanni Francesco Piferrer, Tipografo di S. M., [1804], 24 p.

125 "Stimolato da rispettabili, ed autorevoli Persone a produrre il famoso Oratorio. LA CREAZIONE DEL MONDO [...] non ho esitato un momento in proccurarmi, per ogni possibile mezzo, quanto poteva facilitarmi l'opportunità di soddisfare alle loro brame [...]. [...] ció non ostante m'inquieta non poco il considerare che deve soffrire un pericoloso paralello [... .." La creazione del mondo..., p. [3].

${ }^{126} \mathrm{DdB}$, n. $^{\circ} 133,12-5-1804$, p. 612; DdB, n. ${ }^{\circ} 136,15-5-1804$, p. 624; AHCB, Ms. A 228, CdS XXVIII, pp. 488 (15-5-1804), 505-506 (19-5)

${ }^{127}$ La creazione del mondo..., p. [6]. La lista de los componentes de la compañía italiana del teatro de Barcelona para la temporada 1804-1805, con sus papeles respectivos, en DdB, n. ${ }^{\circ} 78,18-3-1804$, "Suplemento", s. p.

${ }^{128} D d B$, n. ${ }^{\circ} 66,7-3-1805$, p. 298; $D d B$, n. ${ }^{\circ} 69,10-3-1805$, p. 310; $D d B$, n. ${ }^{\circ} 76,17-3-1805$, p. 344 DdB, n. ${ }^{\circ} 78,19-3-1805$, p. 352; DdB, n. ${ }^{\circ} 80,21-3-1804$, p. 364 (Las Estaciones); DdB, n. ${ }^{\circ}$ 82, 23-31805 , p. 372 (Las Estaciones); DdB, n. ${ }^{\circ} 83$, 24-3-1805, p. 376; DdB, n. ${ }^{\circ} 84,25-3-1805$, p. 380; $D d B$ n. ${ }^{\circ} 90,31-3-1805$, p. $408 ; D d B,{ }^{\circ} 91,1-4-1805$, p. 412. 
audiciones de la primera parte de Las Estaciones, trece audiciones completas o parciales de La Creación, de la que la parte más tocada fue, con diferencia, la primera, con once.

\section{Consideraciones finales}

El barón de Maldà, enemigo del "estrépito", tomó la excéntrica decisión de escuchar el estreno del 21 de marzo desde la calle, a través de una ventana abierta de la sala de los veleros ${ }^{129}$. Este gesto solitario, aunque dice mucho de una estética auditiva delicada, heredada del siglo XVIII, no deja de parecer anecdótico. Al contrario, lo que entorpeció la recepción de La Creación en Barcelona no fue la antipatía hacia los imponentes efectivos musicales requeridos por la obra, sino el desafio que representaba para todos los agentes la producción de una obra de aquellas dimensiones. En su literalidad, la insistencia de las fuentes en esta dificultad, la intrínseca de la obra y la logística, indica que el estreno de La Creación en Barcelona fue, como ya había intuido Virella, un acontecimiento excepcional.

También fue insólito por los desplazamientos que supuso en el seno del régimen musical urbano. El éxito de la empresa se apoyó, alterándolas, en las tres tradiciones musicales urbanas que Maldà localizaba en la iglesia, en el espacio doméstico y en el teatro. En la relación problemática que mantenían devoción, consumo estético y mercado musical en la Barcelona de 1804, la recepción de una obra como La Creación de Haydn supuso la aparición de una tensión creativa. Aunque enraizada en el intenso cultivo local del oratorio y en la recepción eclesiástica de Haydn, la ejecución de La Creación implicó para los músicos eclesiásticos locales, sobre todo para los cantores, muchos de ellos ordenados, su aparición pública fuera de la iglesia, y en una sala de conciertos con pago de entrada. En el segundo estreno en el salón del Palau, los cantantes italianos, arrastrados por el espíritu de emulación entre los distintos partidos de aficionados, asumieron, con unos medios insólitos, un desafio situado al margen de sus obligaciones habituales en el marco de la temporada teatral. A pesar de este contexto de emulación mundana, estrechamente relacionado con las academias domésticas, el propósito mismo de estrenar la obra puso en evidencia las limitaciones del modelo de la academia por suscripción, obligándolo a transitar hacia un nuevo modelo con mayores potencialidades, el del incipiente concierto público. Detrás de esta torsión de los esquemas habituales, parece tener un papel destacado la constancia de Joanet Clariana, cuyo inquebrantable compromiso con la obra, reforzado por el sólido prestigio

129 AHCB, Ms. A 228, CdS XXVIII, pp. 278-281 (21-3-1804). Véase también J. J. Carreras: "La recepción de la música alemana...", p. 334. 
público del compositor, lo llevó a apostar por la dificultad sin tener en cuenta el riesgo y convirtió este estreno, ante todo, en un triunfo del ethos del aficionado.

Por su carácter religioso, no escenificado e interpretado (en su primer estreno barcelonés) por músicos eclesiásticos, el oratorio La Creación de Haydn fue visto por Maldà como una obra musical legítima en tiempo de Cuaresma. Así, a disgusto con el teatro religioso declamado que se programó en el teatro de Barcelona durante la Cuaresma de 1807, Maldà declaraba tolerar "solo dramas sacros con plena orquesta y cantatas, como el tan célebre de Haydn de la Creación del Mundo [...], sin ninguna representación de cómicos ni cómicas"130. Pese a la singularidad de su contenido musical y literario ${ }^{131}$, la asimilación de esta obra de Haydn por el público devoto de Barcelona resulta menos llamativa si tomamos en consideración la vigencia de la siesta musical como espacio de consumo estético, de cultivo intenso del oratorio local, a la vez que de importación de repertorios foráneos, y sometido a la emulación entre las capillas musicales y sus respectivos apasionados. De hecho, la colocación de la siesta en la cúspide de la jerarquía de las manifestaciones musicales urbanas y sus concomitancias con la actividad musical doméstica permite entenderla, a pesar de su carácter devocional, como un espacio idóneo para la respetuosa recepción de un repertorio musical exigente o, por retomar los términos de Maldà, lleno de "dificultades y extrañezas".

La línea divisoria entre función y diversión de música trazada por Maldà implica el agrupamiento de fenómenos musicales aparentemente distantes por su inscripción espacial, como la siesta en la iglesia y el concierto espiritual doméstico, o la serenata doméstica por invitación y el concierto público en el teatro con pago de entrada.A su vez, la tripartición jerarquizada propuesta por Maldà entre oratorios, academias y óperas italianas sitúa implícitamente las academias en un espacio intermedio entre los otros dos ámbitos. En efecto, como espacio de superposición y de negociación entre distintos campos musicales urbanos, la temporada de academias acoge el concierto espiritual doméstico en tiempo de Cuaresma y se organiza en torno a alguna de las capillas eclesiásticas de la ciudad, en una selección que responde al gusto de sus respectivos "apasionados", pero, al mismo tiempo, recluta a los cantantes de las sucesivas compañías italianas del teatro y retoma con entusiasmo sus repertorios. La función doméstica

130 "Lo cert és que a molts y a mi no gustan que se representian en aquell lloch profà [el teatro], cosas sagradas, y millor fora, sols dramas sacros ab plena orquesta y cantates, com lo tant cèlebre de Hayden de la Creació del Món, per lo Soberano Autor de totes les coses, sens cap representació de Còmichs ni Còmicas". AHCB, Ms. A 234, CdS XXXIV, p. 132 (16-2-1807).

131 J. Webster: "The Sublime...", pp. 153-155. 
incorporada dentro de la temporada de academias, en tanto que sensible punto de intersección de los distintos elementos en juego, es, precisamente, el lugar en el que primero se manifestará una crisis de convivencia en este modelo de organización de la vida musical urbana en 1797, causado por la secularización de la oferta musical durante la Cuaresma. El ángulo de lectura que ofrece Maldà, así pues, contribuye a dar relieve a las continuidades que existen entre los distintos fenómenos y a comprender mejor las rupturas que los afectan. Entre los elementos de continuidad que enlazan todos los fenómenos descritos, está el de proveer entretenimiento a una sociedad acomodada de tertulias y salones, acotada en sus dimensiones y dominada por el juego permanente de las rivalidades entre distintos partidos de "apasionados", rivalidades que encontramos en todos los niveles de la organización musical urbana, también en torno al concierto público, y a las que hay que reconocer un papel estructurante en iniciativas musicales a veces innovadoras, como la del doble estreno de La Creación de Haydn en Barcelona en la primavera de 1804. 


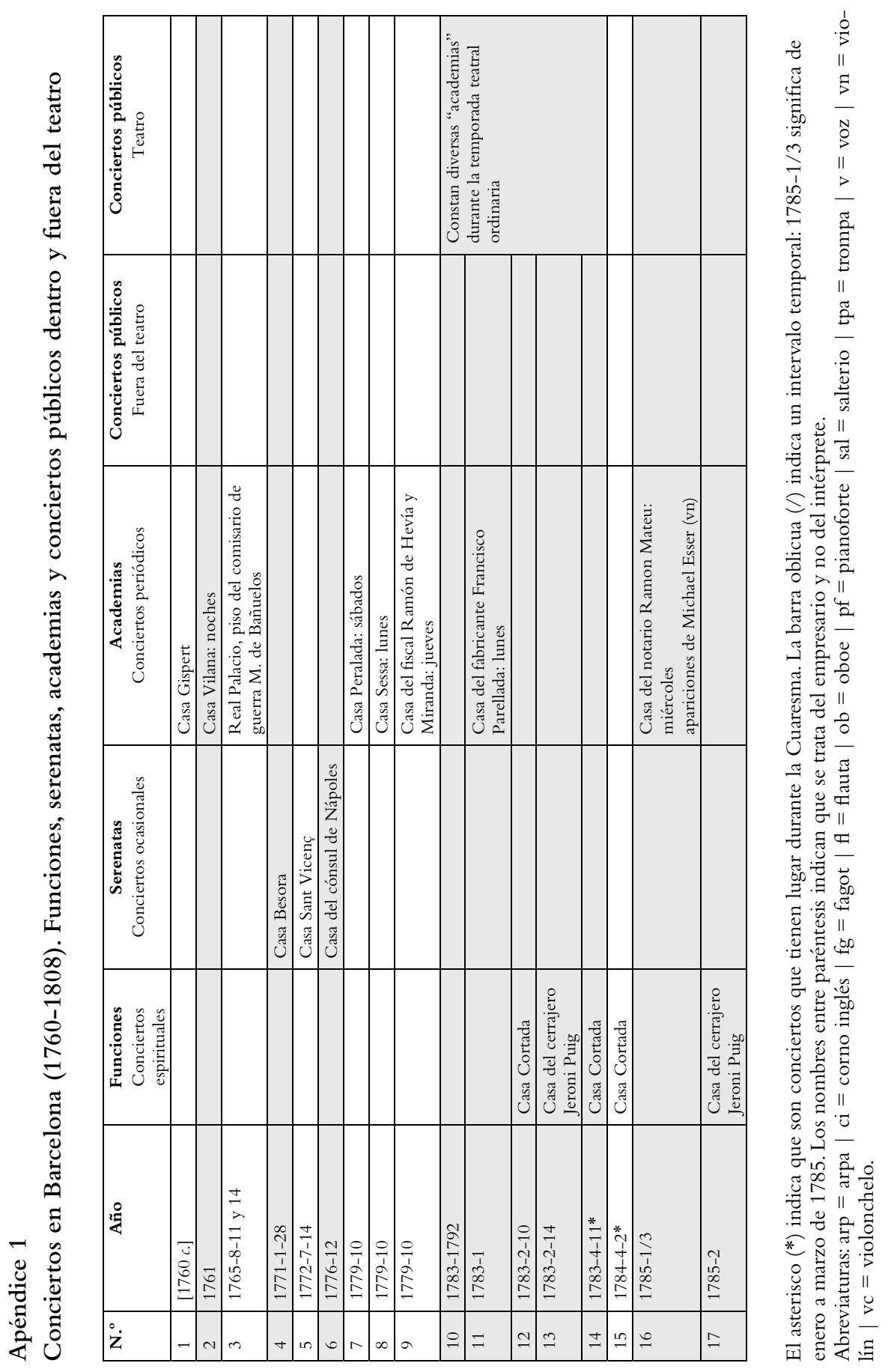




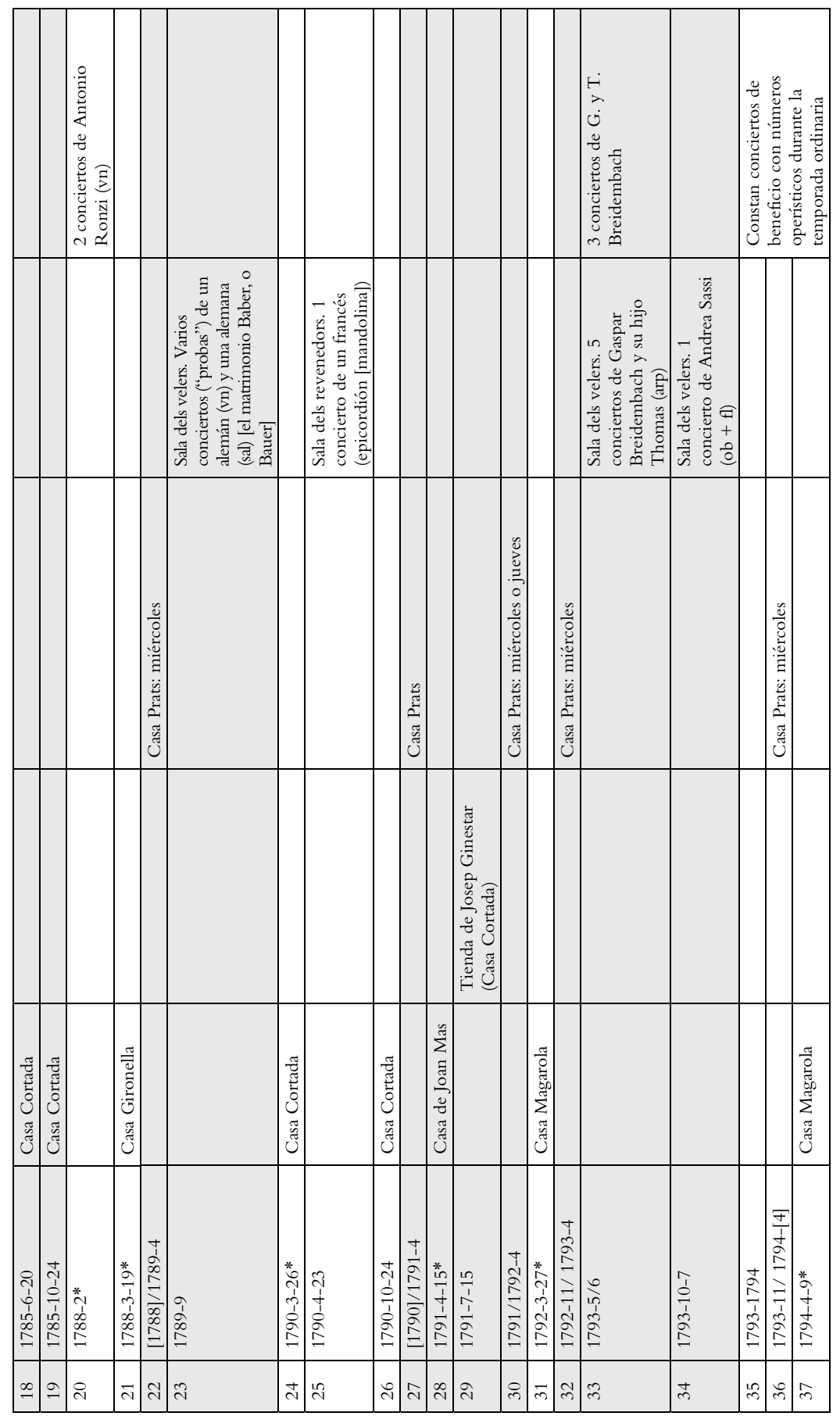




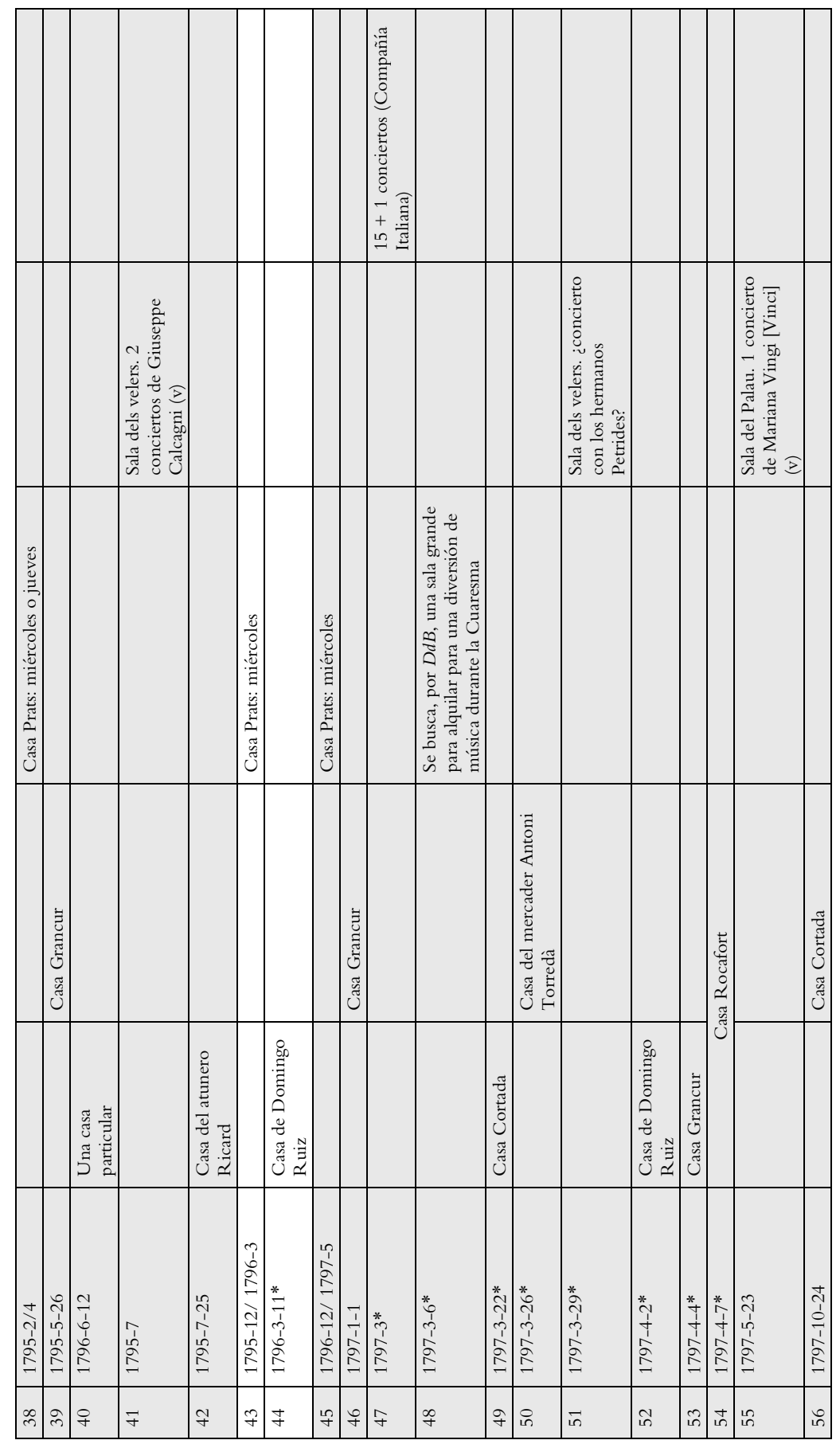


60 Cuadernos de Música Iberoamericana. volumen 3I, $20 \mathrm{I} 8$

\begin{tabular}{|c|c|c|c|c|c|c|c|c|c|c|c|c|c|c|c|}
\hline & 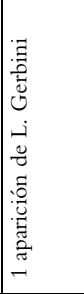 & & & & & & & & & & 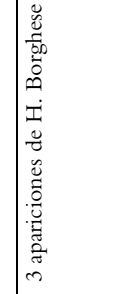 & & & & 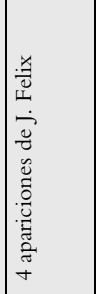 \\
\hline & 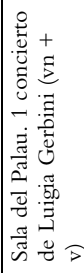 & 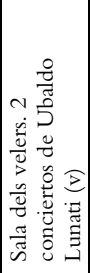 & & 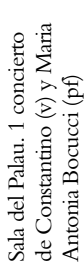 & & & & & & & 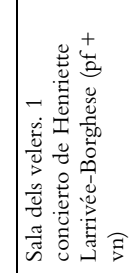 & & & & 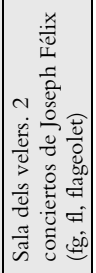 \\
\hline 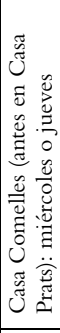 & & & 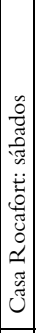 & & 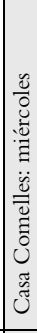 & & & & 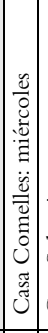 & 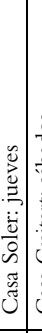 & & 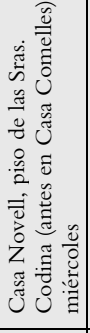 & 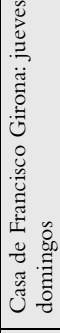 & 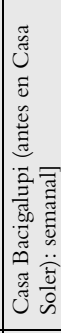 & \\
\hline & & & & & & 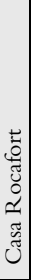 & & 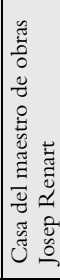 & & & & & & & \\
\hline & & & & & & & 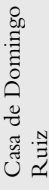 & & & & & & & & \\
\hline 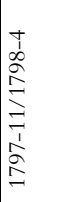 & 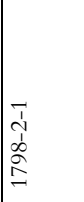 & 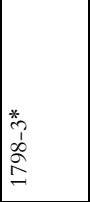 & 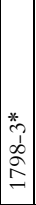 & 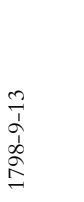 & 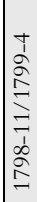 & $\frac{T}{1}$ & 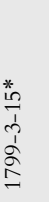 & $\begin{array}{l}0 \\
1 \\
1 \\
1 \\
\alpha \\
\vdots \\
\end{array}$ & 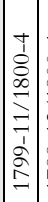 & 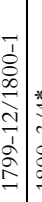 & 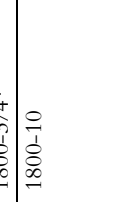 & 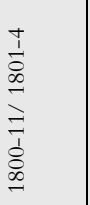 & 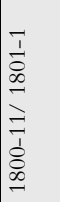 & 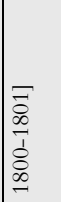 & 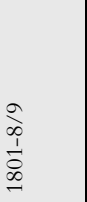 \\
\hline in & $\stackrel{\infty}{i n}$ & in & 8 & $\overrightarrow{6}$ & $\widehat{\sigma}$ & & ţ & 8 & $\stackrel{0}{0}$ & 6 & 88 & 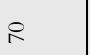 & $\pi$ & 5 & 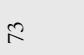 \\
\hline
\end{tabular}




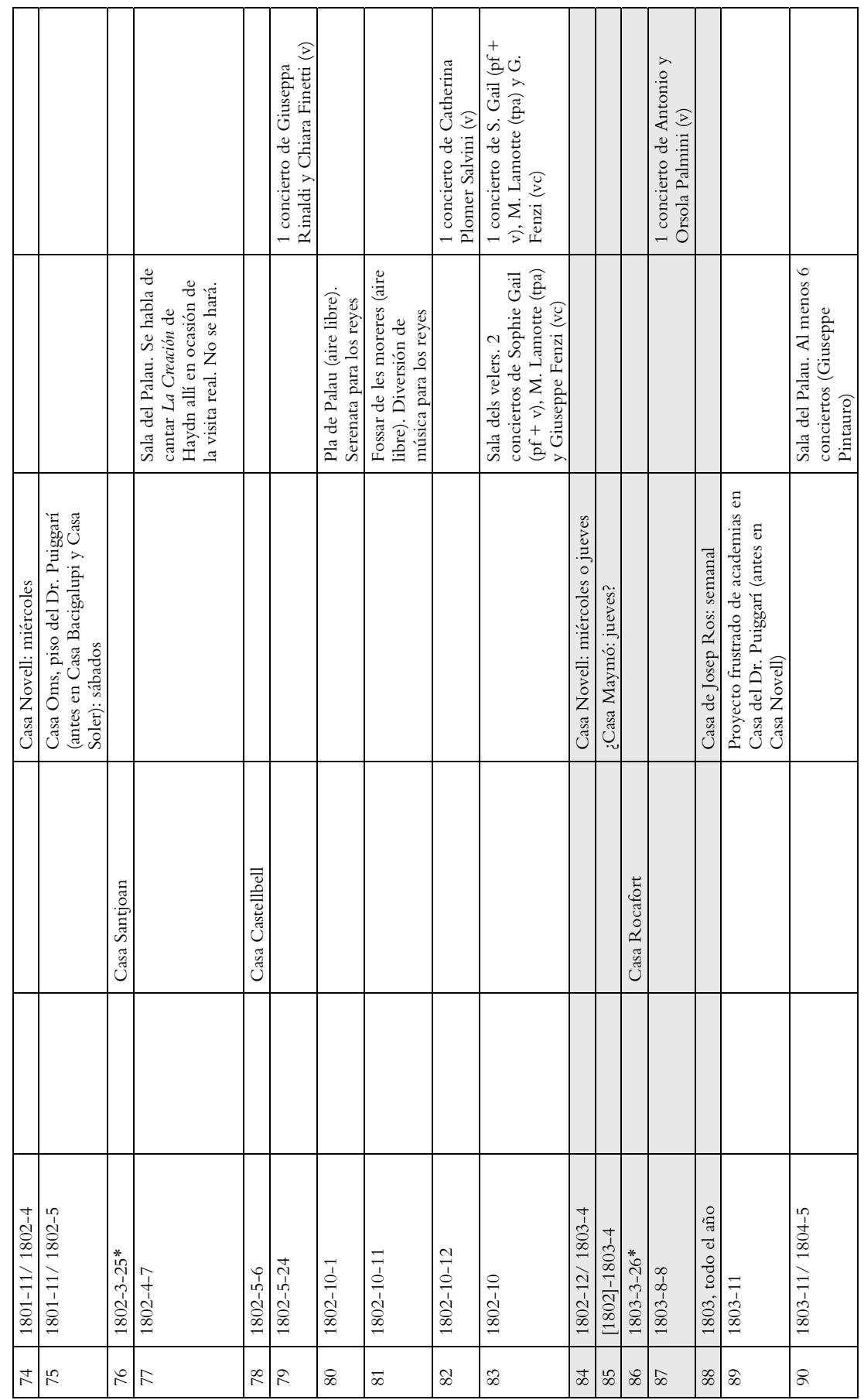




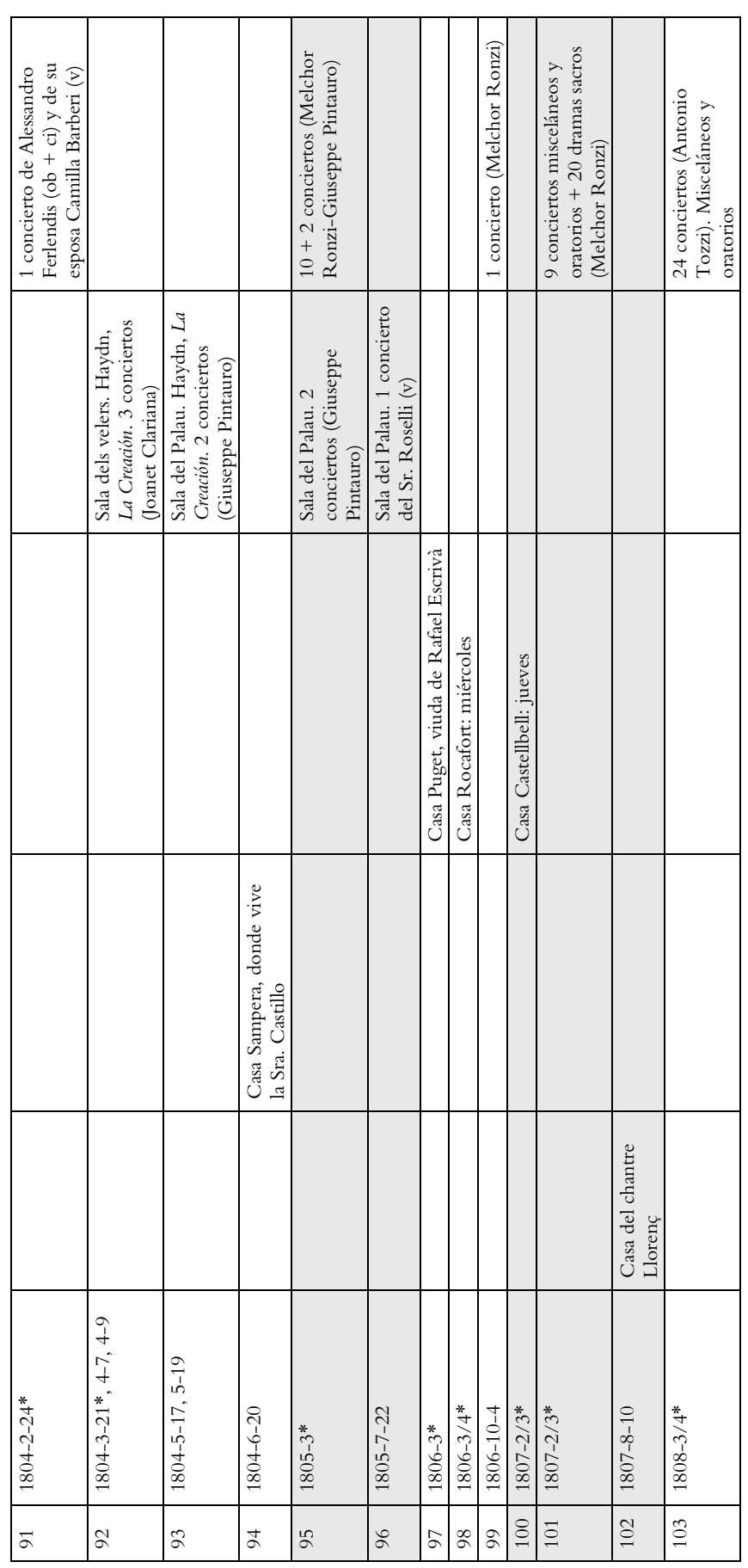

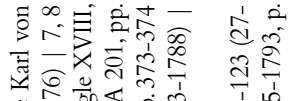

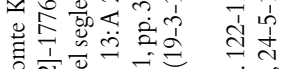

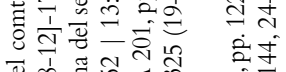
च

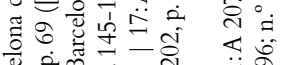

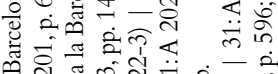

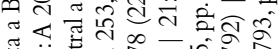

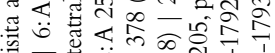

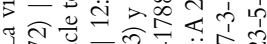

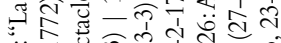

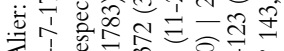

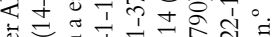
列

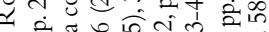
$\ddot{m}=$

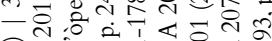

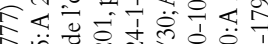
In

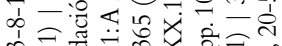

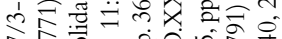

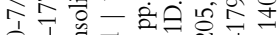

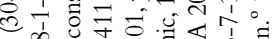

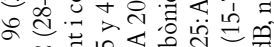

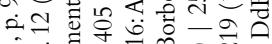

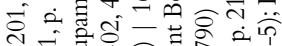

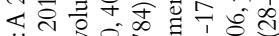
i 4 记

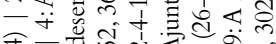

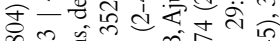

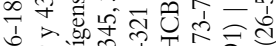

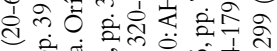
में क्षेत

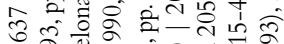
வ

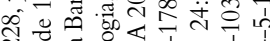

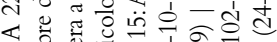

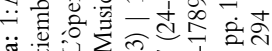

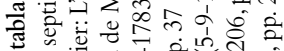

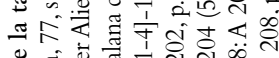

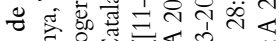
.

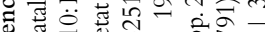

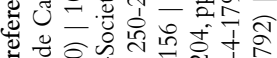

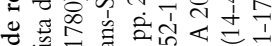

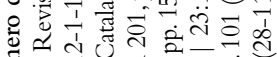
군

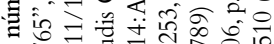

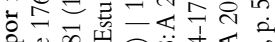

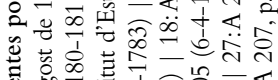

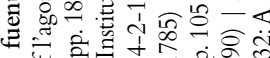

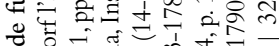

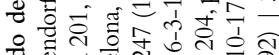

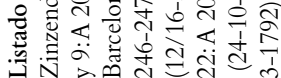




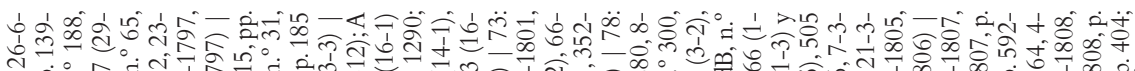

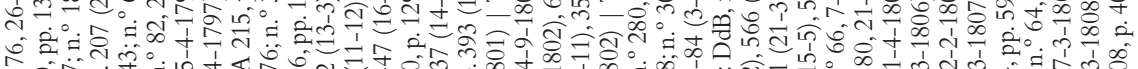

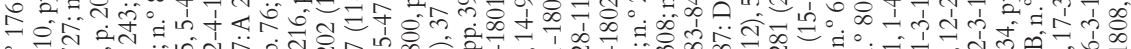

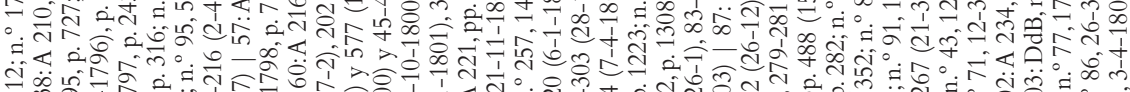

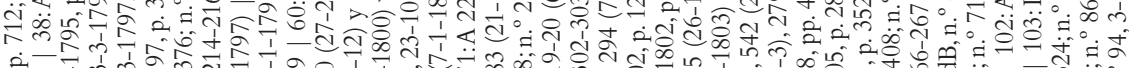

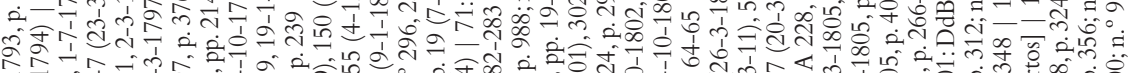

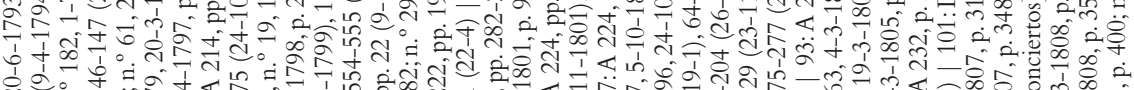

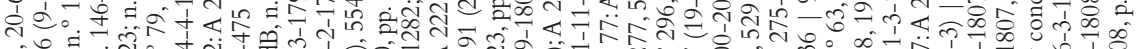

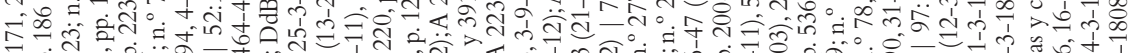
- 0 ,

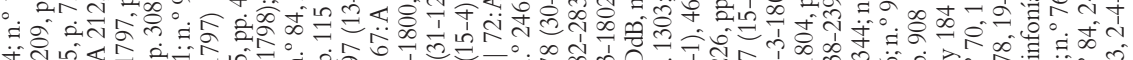

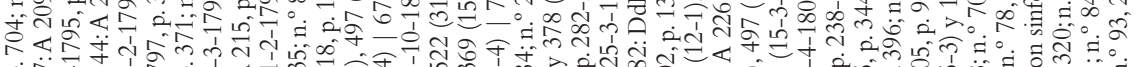

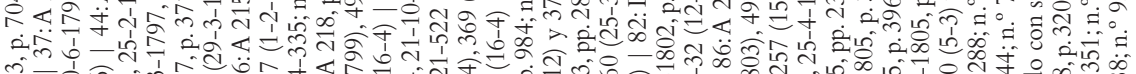

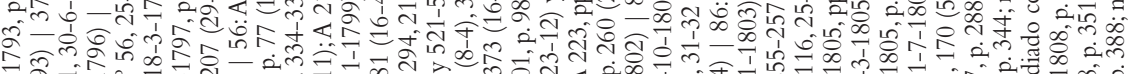
to

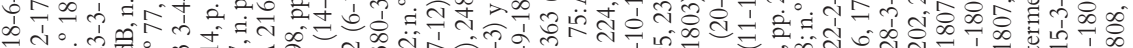

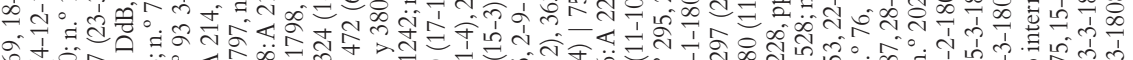

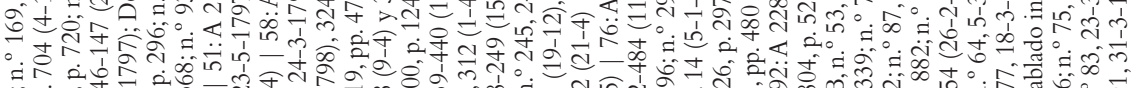
ồ

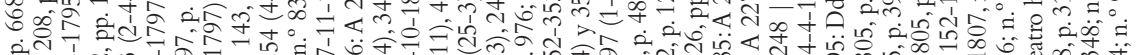

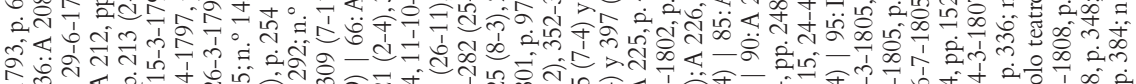

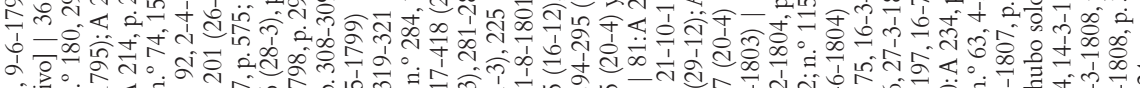
o.

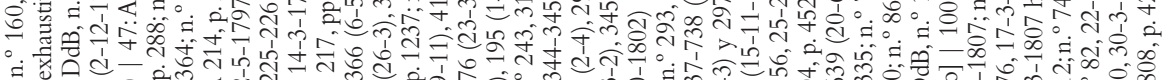
ô o

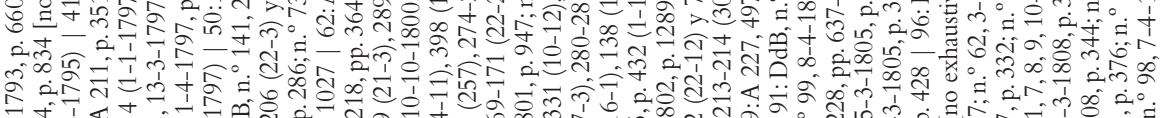

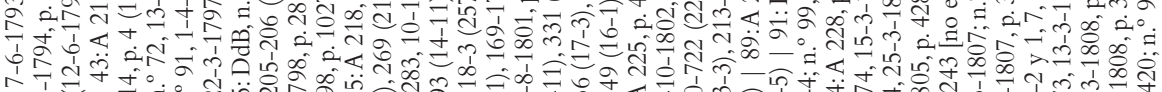

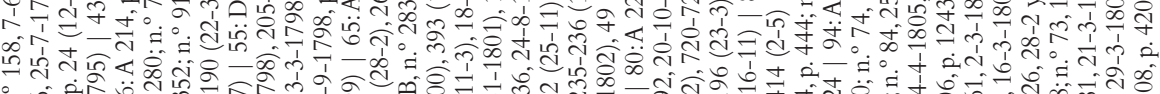

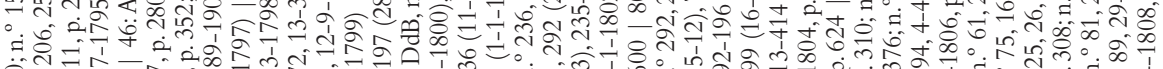

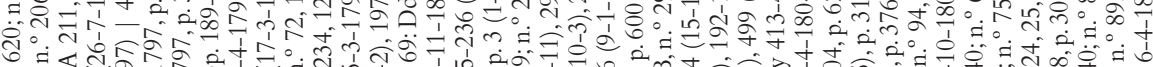

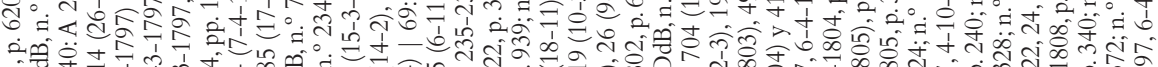

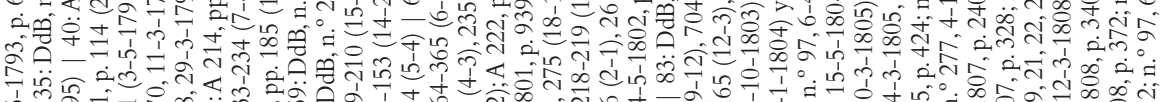

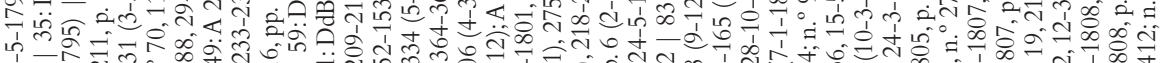

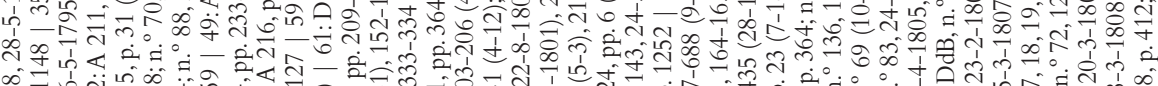

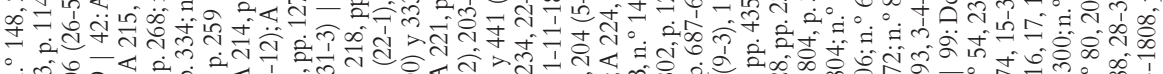

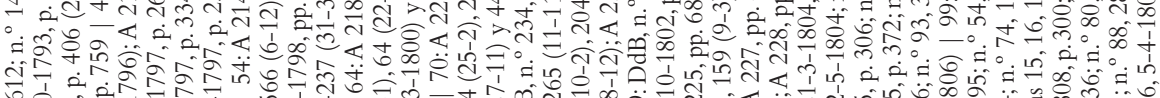
b.

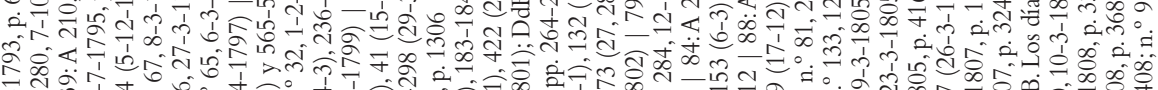

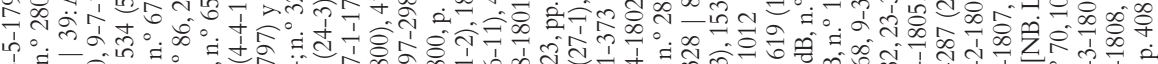

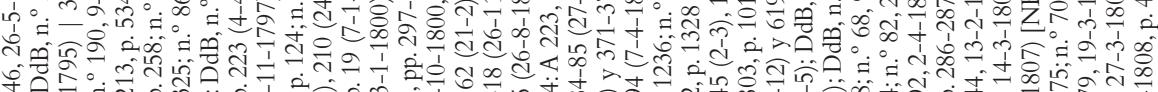

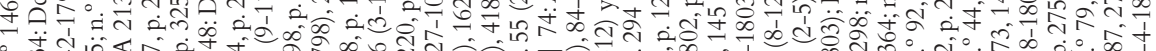

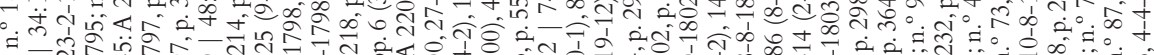

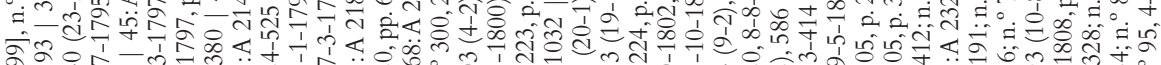

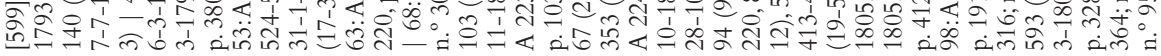




\section{Apéndice 2}

Siesta musical en la iglesia del convento de Santa Maria de Jonqueres (9-3-1801)

Arxiu Històric de la Ciutat de Barcelona, Ms. A 222, Rafael d'Amat i de Cortada, Calaix de sastre XXII, pp. 227-229 (9 de marzo de 1801):

[...] aixis també en la Iglesia de Junqueras Senyoras del Habit de Santiago, que à solicitut y cuydado de más dos Estimadas Fillas religiosas novicias Maria Teresa, y Maria Felipa Amat, ab sas dos compañeras Magarolas també novicias en replegár pecunias per lo Cant del Miserere al Sant Christo; dels Pares; Germans, y demes Personas afectes; no obstant tal Funció de Miserere anár notada à 5 horas de esta tarde en lo Corrent diari estampàt, havent succehit lo Cás de estár los musichs de la Cathedral, ocupats en tal hora en lo cant de un rosari en la Iglesia de Nostra S.ra de la mercè, Festa à Santa Francisca romana, fins à ser llestos de esta Funció los musichs, no han pogut venir à la de Junqueras, que fins à 6 horas tocadas, que encesa la Credensa en la Grada del retaula major, y 4 ciris à una Imatge del Sant Christo sota de un dosér corresponent, y alguna atxa per la Iglesia en candeleros de Ferro, units als musichs de la Seu, los aficionats Individuos tots de la Academia de musica en Casa novell, collocats en un catafal, ó Andamio, inmediat al retaula de millor figura de la Iglesia de Junqueras, en el que cada any, se [228] hi fá lo monument ha comensat luego de trempats tots, luego de haverse alli dut lo Contrabaix, apoyantsi, y fentlo ben roncár lo Agusti; una escullida Sinfonia Concertant; no se si de Hayden ó de Pleyel y acabada, sense dexarsen cap solfa, han comensat lo Segon escullit Miserere, obra de musica del S.r mestre deValencia, del que ne es depositaria, sent regalo fet, Doña Francisca Benages, que en dexarlo per cantar, lo entrega à mano de son confident lo S.r Francisco más ol Mataró contralt de la musica de la Cathedral, est que lo há cantat yá sol y yá à veus, á quatre, y á dos de Mosen Manuel Ducasi xantre del Pi; Lo manel de Vilafranca Clergue tenór de la musica de la Cathedral, y un escolanet de la dita, que ab sa unió, y dels Instruments, era gran melodia en los Passos del Miserere en los termes de tercera major, y tercera menór, que est aixi há comensat suau, y Pizzicato, com musica Funebre, est que se há acabát à 3 quarts de $8 \mathrm{ab}$ prou concurs de Personas de Clase, y de no clase en la Iglesia, haventhi hagut banchs per tothom, preferidas, si bé en seurer en estos las Personas Combidadas; de las Clases de Senyores, y algun Eclesiastich, sent yà Funció esta Eclesiastica, y molt propia en Quaresma; dels no combidats, ni combidadas, no há faltat de estos lo Juan Más entranthi musica de la Cathedral; lo Geperudet Sala, y algun altre que nom recorda. Fins ara, Funció tant tart no se havia vista en la Iglesia de Junqueras, de la que queda yá explicát tot [229] y exitmen yó entremitg de tota aquella broma ab lo xasco de no trobarme lo mocador en la butxaca de la Casaca, que algun pillo, que en tals cocurrencias, se hi barreja, mel haurà fet correr, y paciencia, puix que lo hé perdut, y ventura que men quedan encara mes de una dotsena per socorrer la necessitát del nás, á tenirme de mocár. 


\section{Apéndice 3}

Propuesta de suscripción para unas academias cuaresmales en casa del marqués de Capmany, ca. 1820

Biblioteca de Catalunya, M 3748:

[Se trata de un único bifolio no paginado. En el encabezamiento, en lápiz, de mano moderna, se lee: "Procedència: Fons Ferran de Sagarra i Siscar (Arxiu)".]

Algunos S.es aficionados á la Musica, desean proporcionar á los S. ${ }^{\text {res }}$ de buen gusto de esta Ciudad, academias de Musica escogida, por medio de subscripcion, en un dia de cada semana de las quatro que se siguen de quaresma, $\ddot{y}$ otra en el sabado S. to todas desde las siete hasta las diez de la noche, en la casa Salon del $\Theta^{+}$S. ${ }^{\text {or }}$ Marques de Campmany, en las que se tocarán simfonías, conciertos obligados de varios instrumentos, ÿ piezas de canto de las mas modernas, formando el todo de la Academia ocho piezas entre instrumental ÿ vocal; componiendose $\mathrm{d}$. has academias de 22 Musicos de todos instrumentos, sin contar los Cantores, ÿ todo baxo la direccion del R. do D. ${ }^{\mathrm{n}}$ Antonio Guix [sic?], $\ddot{\mathrm{y}} \mathrm{D} .{ }^{\mathrm{n}}$ Miguel Masip.

Se admiten subscripciones para los gastos que se ofrescan baxo las condiciones siguientes $1^{\mathrm{a}} \quad$ Cada Subscriptor debera entregar por cada academia 8 r.s

$2^{\mathrm{a}} \quad$ A cada subscriptor se le darán quatro targetas de entrada ynclusa la suya

$3^{\mathrm{a}} \quad$ Cada Subscritor deberá prestar quatro sillas decentes, que permaneceran en el salon, hasta concluidas las Academias.

$4^{a} \quad$ Los asientos de todas las sillas, los ocuparan los primeros que concurran á cada una de las academias, sin haber preferencia alguna ni en el lugar, ni en el asiento.

$5^{a} \quad$ A todos se encarga que mientras toque la Musica ó se cante, se observe el mayor cilencio.

$[\mathrm{v}]$

$6^{\mathrm{a}} \quad$ El dinero de la subscripcion, se adelantará por solas dos academias, porque viendose el coste de estas será mas ô menos, el que tengan que satisfacer para las demas, en caso de acomodarles seguir la subscripcion.

$7^{\mathrm{a}} \quad$ Esta subscripcion no tendra lugar, â menos de completarse el num. ${ }^{\circ}$ de cincuenta subscriptores.

$8^{\mathrm{a}} \quad$ Concluidas las academias, se formará un estado de los gastos, para manifestarse á qualquiera subscriptor, que quiera enterarse de él.

$9^{a} \quad$ Cada uno de los Subscriptores, deberá firmar â continuacion de este papel.

[firmado:]

$\begin{array}{ll}\text { Mig. }{ }^{1} \text { O'Doyle } & \text { Anacleto de Pastors } \\ \text { N. de Carles } & \text { F. de Emrana[?] } \\ \text { Jose de Carles } & \text { Xavier de Camps } \\ \text { Heriv. } .^{\text {to }} \text { [?] Vidal } & \text { Luis de Sabater } \\ \text { Jose Ant. }{ }^{\text {O Pellisser }} & \text { Joaq. }{ }^{\text {n }} \text { Gayon } \\ \text { Valentin Comas } & \text { Jayme de Bassols } \\ \text { F. }{ }^{\circ} \text { Rl.[?] } & \text { La de Manresa } \\ \text { Carlos de Osorno } & \text { Vilagaya } \\ & \text { Man. }{ }^{1} \text { Hurtado }\end{array}$




\section{Apéndice 4 \\ Informe sobre la utilización de la sala provisional para espectáculos de acróbatas y conciertos de violín, 7 de marzo de 1788}

Arxiu Històric de la Ciutat de Barcelona, Fons Consell de la Ciutat i Ajuntament Modern, Diversions públiques, 15/1D.XX.1/30:

\section{Copia}

\section{Sirve de exemplar}

Por quanto Josef Fafarello de Nacion Napolitano Autor de una Compañia de Bolatines con los permisos necesarios está dando al Publico varias diversiones que tiene ofrecidas de Saltos, equilibrios, y otros espectaculos en la Sala Provisional dispuesta para las diversiones publicas cobrando media peseta de cada uno de los Espectadores por su entrada, y el alquiler de los Palcos regulado á los mismos precios q. ${ }^{e}$ estan señalados en las temporadas comicas; Y asi mismo Antonio Ronci, Profesor de Violin ha dado dos conciertos con iguales consideraciones proporcionadas á su propio beneficio: Debiendosele prefixar por el Muy Ill. re Ayuntamiento el pago de cierta cantidad afecta por Reales ordenes á beneficio, y utilidad publica proporcionalmente á las ventajas que resultan á ambos Autores de su respectiva diversion. Los infrascritos Comisarios de teatro les señalan esto es al primero la de cinco duros de plata, y al segundo la de un duro de la propia moneda, cuyas partidas deveran respectivamente satisfacer, y poner á disposicion del Gobierno:Y paraque asi se verifique acudan al Mayordomo de Propios de dicho Muy Ill. ${ }^{\text {re }}$ Ayuntamiento el qual en virtud de esta orden les reciba la expresada contribucion librando en favor de dichos interesados el resguardo, y documentos á cada uno corres- $[\mathrm{v}]$ pondientes, y anotando la percepcion al pie de esta misma orden que seguidamente ha de pasar con esta circunstancia al Contador del referido Muy Ill. ${ }^{\text {re }}$ Ayuntamiento a fin de que conservandolo en su poder conste en todo tiempo la concesion, y se haga cargo al referido Mayordomo de dicha partida. Barcelona 7 de Marzo de 1788. $=$ D. ${ }^{\mathrm{n}}$ Fran. ${ }^{\mathrm{co}}$ de Sala, y de Lentorn Reg. ${ }^{\circ}{ }^{\text {o }}$ Com..${ }^{\circ}$ de teatro. $=$ D. ${ }^{\mathrm{n}}$ Cayetano Gispert Reg. ${ }^{\text {or }}$ Comis. ${ }^{\circ}$ de teatro.

Recibido: 26-6-2018

Aceptado: 11-9-2018 